\title{
Why Did Individual Stocks Become More Volatile?
}

\author{
Steven X. Wei and Chu Zhang*
}

March 2003

*The Hong Kong Polytechnic University and The Hong Kong University of Science and Technology respectively. Address correspondence to Chu Zhang, Department of Finance, HKUST, Clear Water Bay, Kowloon, Hong Kong, Phone: (852)-2358-7684; E-mail: czhang@ust.hk. We would like to thank Tim Adam, Keehong Bae, Lewis Chan, Tim Chue, John Heaton, Avanidhar Subrahmanyam, Yexiao Xu, seminar participants at Fudan University, HKUST, University of New South Wales, and especially the referee for their helpful comments and suggestions. Chu Zhang acknowledges the financial support from the Hong Kong RGC Competitive Earmarked Research Grant HKUST6211/00H. All remaining errors are ours. 


\title{
Why Did Individual Stocks Become More Volatile?
}

\begin{abstract}
We investigate why individual stocks become more volatile over the 1976-2000 period, during which quarterly accounting data are available at the firm level. On average, corporate earnings have deteriorated and their volatilities have increased over the sample period. This is more evident for newly listed stocks than for existing stocks. The stock return volatility is negatively related to the return-on-equity and positively related to the volatility of the return-on-equity in cross-sections. The upward trend in average stock return volatility is fully accounted for by the downward trend in the return-on-equity and the upward trend in the volatility of the return-on-equity.
\end{abstract}




\section{Introduction}

The relationship between risk and returns plays an important role in the asset pricing literature. It has long been recognized that both expected return and volatility change over time. Sophisticated econometric models such as GARCH have been developed to characterize the volatility behavior of asset returns. These models assume that conditional volatility of future returns depends on shocks in the current volatility or other state variables, while unconditional volatility is constant over time. It is therefore a surprise that in a recent paper by Campbell et al (2001), the level of average stock return volatility is found to have been increasing over time from 1962 to 1997 in the U.S. Moreover, it is the idiosyncratic stock return volatility that has increased over time, while the volatility of the stock market returns remained basically unchanged. The latter finding echoes another related work by Morck et al (2000) in which the rise of the ratio of idiosyncratic risk to systematic risk in the US stock markets is documented. That the average stock return volatility has been increasing has some profound implications for investors because, as Campbell et al (2001) point out, investors may not always be able to fully diversify their investment portfolios and increased idiosyncratic risks corrode the risk-reward relationship.

In order to understand better the causes and consequences of the increasing stock market volatility, a brief review of the larger literature on the so-called excessive volatility is worthwhile. Shiller (1981) argues that volatility in the stock market index is too high to be accounted for by the variation in subsequent dividends. ${ }^{1}$ A similar phenomenon is also found in the bond market. Roll (1988) examines the relationship at the firm level between corporate events and the stock returns immediately after the events and finds a very low $R^{2}$. The evidence seems to suggest that stock returns are unrelated to the changes in their fundamental values. There is a literature that documents a

\footnotetext{
${ }^{1}$ The issue is clouded by the possibility that corporate managers intentionally smooth dividend payments (Marsh and Merton 1986) and by the assumption used by Shiller that the discount rate for future dividends is a constant (Cochrane 1992).
} 
positive relationship between stock return volatility and trading volume. In a follow-up study to Campbell et al (2001), Malkiel and Xu (2002) suggest that increased volatility has something to do with increased trading activities by financial institutions. The relationship between volatility and trading volume, however, does not directly answer the question of whether stock return volatility is explained by changes in the fundamental value.

From the observation that more developed markets tend to have a higher ratio of firm-specific risk to total risk than emerging markets, Morck et al (2000) argue that the higher ratio actually indicates that more firm-specific information is incorporated into stock prices. Given the difficulty in verifying such a belief in face of the evidence in Roll (1988), Durnev et al $(2000,2001)$ turn to a firm's characteristics and performance over a longer horizon. Their findings indirectly support the notion that a higher ratio of firmspecific risk to total risk reflects a higher informational efficiency in the stock market. However, the question of why the absolute level of firm-specific volatility increased over time remains to be answered.

In a more recent paper by Pástor and Veronesi (2002), firm characteristics including return volatility are analyzed in a rational asset pricing framework. Learning for profitability induces an age effect, which implies that newly listed firms tend to have higher return volatility. In this paper, we examine the causes of increasing volatility in stock returns empirically and, in particular, we try to answer two specific questions. The first question pertains to the extent to which the upward trend in the average return volatility can be attributed to the changes in the fundamentals of firms. The second question pertains to the division of the upward trend in the average stock return volatility between existing stocks and newly listed stocks. ${ }^{2}$

Perhaps no researcher would deny the role of fundamental variables in determining stock prices. The question often centers on whether the variation in stock prices is fully

\footnotetext{
${ }^{2}$ Pástor and Veronesi (2002) also address the related issues. But their empirical analysis is on the cross-sectional relations, rather than on the upward trend in the average return volatility.
} 
explained by changes in the fundamental variables. A growing literature on behavioral finance emphasizes investors' irrational behavior as an additional explanation for the variation in stock prices that is not explained by the fundamentals. Anecdotal evidence on fashions, fads and bubbles in the financial markets seems to support the view that, from time to time, stock prices are subject to errors. But even with the extreme view of inefficient markets, these errors are not totally random. They often take the form of underreaction or overreaction to the information in the fundamental variables. Therefore, understanding the effect of fundamental variables on the stock return volatility is crucial to resolving the issue of excess volatility. For an upward trend in stock return volatility that lasted for about four decades, a thorough understanding of the impact from these fundamental variables is indispensable.

From the fundamentalist point of view, stock prices equal the sum of all the discounted future dividends. Indeed, Pástor and Veronesi (2002) document a strong crosssectional relationship between return volatility and dividend yield. Dividends, however, are under the discretion of corporate managers who normally set dividend payout ratios to meet their companies' long term growth needs and often iron out the wrinkles in corporate earnings to provide smooth dividend payments. As Lintner (1956) and Marsh and Merton $(1986,1987)$ point out, the time-series relationship between the return volatility and the dividend volatility may often be distorted. We, therefore, focus on earnings rather than on dividends. Although earnings can be manipulated by managers too to some extent, excessive manipulation is not without the risk of criminal investigation as recent events indicate. Earnings, therefore, reflect more information about future profitability of the firm than do dividends which are under complete legitimate discretion of the managers. A recent paper by Vuolteenaho (2002) points out that firm-level stock returns are mainly driven by cash-flow news. His finding is also based on firm-level earnings.

We find two variables that are useful in explaining the upward trend in the average 
stock return volatility. One is the average return-on-equity, which is the earnings divided by the book-value of equity. The other is the average sample variance of the returnon-equity in the past three years. Using the data from 1976 to 2000 in the US stock markets, we document that the equally weighted average return-on-equity declined while the equally weighted sample variance of return-on-equity rose. These two factors explain most of the upward trend in the equally weighted return variances and all of the upward trend in the value-weighted return variances. This conclusion holds for the average variances of both raw returns and market-adjusted returns. The findings make economic sense. Since stock prices are discounted value of future profits and return volatility is the reflection of the uncertainty about future profits. Therefore, stock return volatility is naturally driven by the uncertainty about future profits. The stock return volatility is also negatively related to the past earnings because low earnings signal bad time ahead and cause more investors' jitters.

We also explore other fundamental variables, such as firm size, firm age, leverage, and the book-to-market equity ratio, for their role in explaining the upward trend in return volatility. Although some of these variables themselves have cross-sectional explanatory power for return volatility at the firm level, the averages of these variables do not have trends over time in the direction that can be responsible for the upward trend in return volatility.

The second question we try to answer in this paper regards how the increased average return volatility is divided between existing firms and newly listed firms. From the beginning to the end of the sample period we analyze, the number of stocks has more than doubled. Many newly listed firms tend to have higher growth potentials and higher return volatilities that contribute to the higher average return volatility. A quantitative measure that separates the two sources of the increased average volatility can help us understand better the nature of the increase. We find that of the upward trend in the equally weighted average variance of returns, about one-third is attributed to existing 
firms and about two-thirds is attributed to newly listed firms. For the value-weighted average variance of returns, the division is roughly half and half.

The rest of this paper is organized as follows. Section II presents a simple model that motivates the link between stock return volatility and the uncertainty in fundamental variables such as earnings. Section III describes the data we use in this study and presents simple statistics on the average return variances, average return-on-equity, and average sample variance of return-on-equity. Some preliminary analysis is also provided. Section IV establishes relationships between return variance and the two explanatory variables at the firm level in cross-sectional regressions. Section $\mathrm{V}$ then presents the main results that the uncertainty in earnings variables explain most of the upward trend in the average return variances. The last section concludes the paper.

\section{Motivation}

There are many factors that may cause stock return volatility to change. Instead of resorting to the behavioral explanations that rely on investors' irrationality, we examine fundamental reasons in this paper. In the fundamentalist view, stock prices are the sum of its expected future payoffs discounted at the appropriate discount rates. Based on the dividend growth model, Campbell and Shiller (1988) derived a log-linear model that relates unexpected stock returns to the changes in expected future dividends and changes in the future discount rates. Using a theoretical accounting relationship known as clean surplus, Vuolteenaho (2002) transformed the dividends in the Campbell-Shiller model to return-on-equity (i.e., earnings divided by the book value of equity) as follows,

$$
r_{i t}-E_{t-1} r_{i t}=\Delta E_{t} \sum_{j=0}^{\infty} \rho^{j}\left(e_{i, t+j}-f_{t+j}\right)-\Delta E_{t} \sum_{j=0}^{\infty} \rho^{j} r_{i, t+j}+\kappa_{i t}
$$

where $r_{i t}$ is the return on stock $i$ in period $(t-1, t), e_{i, t+j}$ is the return-on-equity in period $(t+j-1, t+j), f_{t+j}$ is the riskfree rate for period $(t+j-1, t+j), \rho$ is a constant slightly less than one, and $\kappa_{t}$ is an approximation error. In the expression, $E_{t-1}$ is the 
expectation conditioned on the information available at $t-1$ and $\Delta E_{t}=E_{t}-E_{t-1}$ is the change in expectation from $t-1$ to $t$. Vuolteenaho finds that, for individual firms, most variation in the return comes from the first term (the cash flow news) rather than the second term (the discount rate news). For a typical stock, the former is more than twice larger than the latter. As a first approximation, therefore, we can focus on the conditional variance of the cash flow news in studying the return volatility. The relationship we examine in this paper takes the form

$$
\operatorname{Var}_{t-1}\left(r_{i t}\right)=\operatorname{Var}_{t-1}\left[\Delta E_{t} \sum_{j=0}^{\infty} \rho^{j} e_{i, t+j}\right]+\xi_{i, t-1}
$$

where $\xi_{i, t-1}$ encompasses the variances in the discount rate news, the error term $\kappa_{t}$, the riskfree rate, and all the covariance terms. ${ }^{3}$

In the empirical analysis below, we adopt a non-parametric approach in constructing the conditional variance of the cash flow news without modelling the stochastic process for the return-on-equity. However, some clues of how to construct the conditional variance can be gleaned from a simple parametric model which we now turn to. Suppose $e_{t}$ follows an $\mathrm{AR}(1)$ process with conditional heteroskedastic error terms,

$$
\begin{aligned}
e_{i t} & =\gamma_{0}+\gamma e_{i, t-1}+u_{i t} \\
\operatorname{Var}_{t-1}\left(u_{i t}\right) & =g\left(u_{i, t-1}^{2}, \ldots, u_{i, t-k}^{2}, u_{i, t-1}\right)
\end{aligned}
$$

where $g$ is a function increasing in $u_{i, t-1}^{2}, \ldots, u_{i, t-k}^{2}$, and decreasing in $u_{i, t-1}$. The positive relation between $\operatorname{Var}_{t-1}\left(u_{t}\right)$ and $u_{t-1}^{2}, \ldots, u_{i, t-k}^{2}$ reflects the ARCH effect found in many economic time series that volatilities tend to cluster. The negative relationship between $\operatorname{Var}_{t-1}\left(u_{t}\right)$ and lagged terms $u_{t-1}$ is the good-news-and-bad-news effect: a pleasant surprise in the last period earnings makes the uncertainty about this period earnings smaller while a unpleasant surprise makes the uncertainty larger. The cash flow news in this

\footnotetext{
${ }^{3}$ Vuolteenaho finds that the error term $\kappa_{i t}$ is very small and that the covariance between the cash flow news and the discount rate news is also small.
} 
case can be easily found to be

$$
\Delta E_{t} \sum_{j=0}^{\infty} \rho^{j} e_{i, t+j}=\frac{1}{1-\rho \gamma} u_{t} .
$$

As a result,

$$
\operatorname{Var}_{t-1}\left(r_{i t}\right)=\frac{1}{(1-\rho \gamma)^{2}} g\left(u_{i, t-1}^{2}, \ldots, u_{i, t-k}^{2}, u_{i, t-1}\right)+\xi_{i, t-1} .
$$

The simple model implies that the realized ROE volatility and realized ROE itself in the past are part of the conditional total variance of the return. Any trend in the return volatility can be potentially induced from the trend in ROE volatility and the trend in ROE itself. These properties will guide us in choosing variables that can explain the trend in the return volatility.

At this point, we should clarify our use of the term "trend". Although we will use a linear function of time to fit the average return volatility in the time-series analysis in a later section, as did Campbell et al (2001), it is not our intention to affirm that there is any deterministic trend or a stochastic trend in the average return volatility. ${ }^{4}$ Instead, our purpose in this paper is to establish the link between the return volatility and volatility of the fundamental variables and to confirm the sources of the rise in the average return volatility.

Even when individual firms do not exhibit any trend in their earnings and the earnings volatility, the cross-sectional average earnings and average earnings volatility may have trends if the components of the average change over time. It will be shown later in the paper and it has been shown elsewhere in the literature (e.g. Fama and French 2001) that the number of firms listed in the major U.S. stock markets has increased dramatically in the last twenty years and the newly listed firms tend to be smaller, with

\footnotetext{
${ }^{4}$ In Campbell et al (2001), formal tests reject the hypothesis that return volatility series contain a unit root, excluding the case of stochastic trend. Since the sample we use in this paper differs from that of Campbell et al (2001), we also conduct a unit root test based on the augmented Dickey-Fuller $\rho$-tests and t-tests. The results sometimes depend on whether lagged difference terms are used to account for serial correlation and on whether a deterministic trend is allowed in the model. For most average return volatility series, the unit root hypothesis is rejected at $5 \%$ significance level. These results are not reported because they do not have direct bearing on the issues we tackle in this paper.
} 
lower and more volatile earnings. How much this contributes to the increasing return volatility is also part of the questions we will try to answer in this paper.

\section{Data and Preliminary Analysis}

\section{A. The Sample}

The data we use in this paper are from the Center for Research in Stock Prices (CRSP) at the University of Chicago and Compustat. CRSP has daily return data from 1962 to 2000. Compustat has quarterly accounting data from 1971 to 2000 . A stock is included in our sample if it has daily stock return data in a particular month, and quarterly earnings for the past three years. The past earnings are used to calculate the sample variance of the return-on-equity, which is the earnings divided by the book-value of equity. Only stocks with positive book-value of equity are included in the sample. The sample period we choose is from January 1976 to December 2000.

In order to see how return volatility changes over time, we divide the entire sample period of 1976-2000 into several subperiods of five years. Panel A of Table 1 lists the average numbers of firms in the various subperiods. The number of firms varies from month to month, but on average there are 2150.25 firms in 1976-1980, 2161.62 firms in 1976-1985, and so on. The average number of firms increases over time. The increase is slow initially, but accelerates quickly. In the last five-year subperiod, there are a total of 4862.27 firms in the sample.

Table 1 here

\section{B. Variance of Returns}

We use two definitions of return volatility, following Campbell et al (2000). The variance of raw returns, denoted as $\mathrm{VR}_{i t}^{\text {raw }}$ where $i$ stands for a stock and $t$ a month, is defined as 
the sample variance of daily raw returns within the month, multiplied by the number of trading days in the month. The variance of market-adjusted returns, denoted as $\mathrm{VR}_{i t}^{a d j}$, is defined as the sample variance of daily returns on stock $i$ in excess of the daily return on the value-weighted market portfolio, multiplied by the number of trading days in the month. The value-weighted market portfolio here is calculated using stocks in the sample.

In each month, $t$, we denote the equally weighted and value-weighted cross-sectional average variances of raw returns as $\mathrm{VR}_{e w, t}^{r a w}$ and $\mathrm{VR}_{v w, t}^{r a w}$, where value is the market capitalization of stock $i$ in the beginning of month $t$. We also calculate the variance of marketadjusted returns. The monthly variance of market-adjusted returns, $\mathrm{VR}_{i t}^{a d j}$, is defined the same as that for raw returns except the daily raw returns are replaced by the difference between the raw returns on stock $i$ and the value-weighted average market returns. The equally weighted and value-weighted average variances are then denoted as $\mathrm{VR}_{e w, t}^{a d j}$ and $\mathrm{VR}_{v w, t}^{a d j}$. As Campbell et al (2001) show, when the sample includes all the stocks in the market portfolio, the value-weighted average variance of the market-adjusted returns, $\mathrm{VR}_{v w, t}^{a d j}$, is the same as the value weighted average variance of the idiosyncratic returns. The equally weighted average variance of the market-adjusted returns, $\mathrm{VR}_{e w, t}^{a d j}$, does not have the same interpretation, but it nevertheless provides important information. We follow Campbell et al (2001) in using the market-adjusted return, rather than estimating the betas and calculating the idiosyncratic returns because a constant-beta market model does not describe the data very well.

For a given subperiod, the simple time-series average of the average variances is calculated across all the months in the subperiod and is reported in Panel A of Table 1. For easy comparison, the reported monthly variances are multiplied by 1200 as Campbell et al (2001) did. From these simple averages, we make three observations on the return volatility. First, the equally weighted average variance of the raw returns in 1996-2000 is around 60, more than triple that of 18.82 in 1976-1980. Second, the value- 
weighted average increases to 19.49 in 1996-2000, almost triple that of 6.75 in 1976-1980. Third, in various subperiods, the equally weighted average variances are about two to seven times as large as the value-weighted average variances, indicating that the stocks of smaller firms are typically more volatile. We also notice that the trends in return volatility are not monotonic. The 1987 stock market crash obviously plays a role in the non-monotonicity.

The fact that both equally weighted and value-weighted average variances of returns for 1996-2000 are triple those for 1976-1980 reconfirms what Campbell et al's (2000) finding that the trend in return volatility is not caused only by stocks from small firms. There is a difference, however, between equally weighted and value-weighted averages of return variances. The equally weighted variance of returns tends to move upward quite evenly in the 1981-2000 period, while the value-weighted average variance of returns shoots up mostly in the last five-year period 1996-2000.

Campbell et al (2001) show that an upward trend in return volatility is not seen in the market portfolio, so the phenomenon is the one for individual stocks. Their finding is reconfirmed here for various subperiods. All the average variances of the market-adjusted returns are smaller than those of the raw returns, but the differences are small, except for the 1986-1990 subperiod, which does not stand out as a high volatility period because the effect from the 1987 market crash is removed from the market-adjusted returns. The patterns in the average variances of market-adjusted returns are very much the same as those of raw returns. The average variances in the 1996-2000 subperiod are nearly tripled compared with the 1976-1980 subperiod.

\section{Incremental Variance of Returns}

Since the number of stocks increases over the sample period, the average variance of returns at different times is calculated over different samples of stocks. An upward trend in the average variance of returns can be caused by an increase in return volatility 
of existing stocks and by a higher return volatility of newly listed stocks. ${ }^{5}$ One of the important questions we try to answer in this paper is how much the increase of the average return volatility is attributed to an increase of return volatility of existing firms and how much to a higher return volatility of newly listed firms.

One way to answer the question just posed would be to examine firms that existed from certain date only to see if the volatility of their stocks increases over time. This, however, may induce a bias. For a given point in time, existing firms consist of firms that will survive in the future and firms that will exit later. The average return variance for surviving firms obviously has a survivorship bias that is not easy to correct. This is true because the contribution to the average return volatility made by firms that eventually exit tend to be increasing over time before they exit and zero afterwards, so the net effect of including these firms in calculating time-series average variances is ambiguous. In this subsection, we consider the use of incremental variances of returns instead.

For a stock $i$ in month $t$, the incremental variances of raw returns is defined by

$$
\mathrm{IVR}_{i t}^{r a w}=\mathrm{VR}_{i t}^{r a w}-\overline{\mathrm{VR}}_{i s}^{r a w}
$$

where $\overline{\mathrm{VR}}_{i s}^{\text {raw }}$ is an estimate of the initial return variance, calculated as the simple average of return variances in the first twelve months in the sample in which the return, the return-on-equity and sample variance of the return-on-equity are available. ${ }^{6}$ The initial return variance of a firm that exits in the beginning of 1976 is taken as that of 1976 . We require that the stock have at least twenty-four months of data, so the sample of stocks is slightly smaller than before. The equally weighted and value-weighted averages of incremental variances of raw returns are denoted as $\operatorname{IVR}_{e w, t}^{r a w}$ and $\operatorname{IVR}_{v w, t}^{r a w}$, respectively. The equally weighted and value-weighted averages of incremental variances of marketadjusted returns can be similarly defined and denoted as $\operatorname{IVR}_{e w, t}^{a d j}$ and $\operatorname{IVR}_{v w, t}^{a d j}$. The

\footnotetext{
${ }^{5} \mathrm{~A}$ third possibility that delisted firms tend to have lower return volatility can be ruled out because, empirically, delisted firms are found to have higher return volatility, especially right before they exit.

${ }^{6} \mathrm{We}$ also tried alternative definitions of initial return variance. For example, the first month is left out to avoid a possible initial-public-offering effect. These alternative definitions do not make material differences.
} 
average incremental variances of returns remove the possible higher return volatility for newly listed firms and, therefore, reflect the increase in return volatility for existing firms only. If the return volatility of existing firms is constant over time, then the incremental variance of returns should be approximately zero. The calculated incremental variances of returns, raw and market-adjusted, for various subperiods are reported in Panel B of Table 1.

The equally weighted averages of incremental variances, which are dominated by smaller firms, are from $1 / 3$ to $1 / 2$ of the increments of the corresponding average variances in Panel A. For example, in Panel A, the equally weighted average variance of raw returns has an average of 18.82 for 1976-1980 and 60.09 for 1996-2000, with an increment of 41.27, while in Panel B, the corresponding numbers are -1.46 and 13.80, an increment of 15.26. A similar pattern is found for variances of market-adjusted returns.

The value-weighted averages of the incremental variances of the raw returns and of the market-adjusted returns show a different pattern. They are barely different from zero except for 1996-2000. The value-weighted averages of the incremental variances of returns in 1996-2000 are about half of the incremental value-weighted average variance from 1976-1980 to 1996-2000. The difference between the equally weighted averages and the value-weighted averages is not surprising. Many of the firms are delisted because of financial distress. Delisting happens when a firm loses its market value and becomes volatile. As a result, the impact on return volatility is more pronounced in the equally weighted averages of return variance, which are more influenced by small firms than are the value-weighted averages of return variances.

\section{Graphical Analysis of Variance of Returns}

The patterns presented in Table 1 can be illustrated graphically. Figure 1 presents the time-series plot of the average variance of raw returns and the average incremental variance of raw returns. The pictures of the variances of the market-adjusted returns 
look very similar to those of the raw returns and, therefore, are not presented here.

Figure 1 here

The top panel of Figure 1 shows the equally weighted averages. The thin solid line representing the average variance of returns for all firms shows a division between 19761985 and 1986-2000. In the former period, return volatility is tame while in the latter period it becomes wild. The dashed line is for newly listed firms only where a firm is defined to be a new list if it is within twelve months of being listed. As we can see, newly listed firms tend to have higher return volatility than the existing firms and there is an obvious trend in their return volatility. The heavy line representing the average incremental variance creeps near to zero in 1976-1985 and jumps up and down with the thin line to a lesser extent in 1986-2000.

The bottom panel of Figure 1 is the time-series plot of the value-weighted averages of variance of the raw returns and the value-weighted average of the incremental variance of the raw returns. Unlike the top panel, the two solid lines stay low for most of time and move up and down gently in tandem. The only signs of an upward trend in these lines are the spike for the 1987 stock market crash and the run-up in the last few years.

Overall, the figure reinforces the notions that return volatility is stable in the 19761985 period and that, as many new companies are listed in the 1986-2000 period, the return volatility increases, especially for smaller firms. The return volatility of large firms increases mainly in the 1996-2000 period.

\section{E. Return-on-equity (ROE) and Its Sample Variance (VROE)}

Return-on-equity, $\mathrm{ROE}_{i t}$, for stock $i$ in month $t$ is the stock's most recent quarterly earnings divided by the book value of equity. We use the (quarterly) earnings report date in Compustat to determine when the accounting information is available. It is typically available within three months after the end of a firm's fiscal quarter. 
Most observations of ROE fall in the interval of $(-0.5,0.5)$. However, there are some extreme values that lie outside the interval. To avoid spurious inferences from these extreme values, we winsorize the observations at -0.5 and 0.5 . Out of 613337 stockmonth observations, there are 3945 stock-months, or $0.6432 \%$, with an ROE greater than 0.5, and there are 16351 stock-months, or $2.6659 \%$ with an ROE less than -0.5 . The equally weighted and value-weighted average ROEs are denoted $\mathrm{ROE}_{e w, t}$ and $\mathrm{ROE}_{v w, t}$. Panel A of Table 1I reports the time-series average $\mathrm{ROE}_{e w, t}$ and $\mathrm{ROE}_{v w, t}$ for subperiods of 1976-2000. The quarterly ROEs are multiplied by 400 in the table.

\section{Table 2 here}

It is obvious from Panel A of Table 2 that the equally weighted average ROE and the value-weighted average ROE are very different. First, equally weighted average ROEs are much smaller than value-weighted average ROEs. Second, they exhibit different trends. The equally weighted average ROE declines persistently, from $9.73 \%$ in 1976 1980 to $0.30 \%$ in $1996-2000$ while the value-weighted average ROEs are stable in the range of 11 to $14 \%$ for most of the time and actually increases to $16.20 \%$ in the last five-year subperiod.

The variance in return-on-equity used in this study, $\mathrm{VROE}_{i t}$, for stock $i$ and month $t$ is the sample variance of quarterly ROEs over the last three years. The equally weighted and value-weighted average VROEs in month $t$ are denoted as $\mathrm{VROE}_{e w, t}$ and $\mathrm{VROE}_{v w, t}$, respectively. The time series means of $\mathrm{VROE}_{e w, t}$ and $\mathrm{VROE}_{v w, t}$ in various subperiods of 1976-2000 are also reported in Panel A of Table 2. As average ROEs, the numbers for VROEs are also multiplied by 400. From the table, we see that the variance in return-on-equity has increased over time on average. The equally weighted averages of VROE are greater than the value-weighted averages, indicating that small firms tend to have larger variances in ROE.

The two variables, ROE and VROE, can be viewed as inputs of a special nonpara- 
metric estimator of the conditional variance function (6) in Section II. VROE reflects the ARCH-like effect, while ROE itself reflects the asymmetric feature of the conditional return variance with the past realized shock because the predictable part of ROE is relatively small. Since the purpose of this paper is not to test any specific parametric model, the use of ROE and VROE qualitatively captures the idea that the uncertainty about the future ROE is positively related to the realized variation of past ROEs and negatively related to the realized ROE itself.

\section{F. Incremental ROE and Incremental VROE}

The incremental ROE and VROE for stock $i$ and month $t$ are defined similarly where the initial ROE is calculated as the simple average of ROEs in the first twelve months of the sample when returns, ROEs and VROEs are all available. For month $t$, the equally weighted and value-weighted average incremental ROEs are respectively denoted as $\operatorname{IROE}_{e w, t}$ and $\mathrm{IROE}_{v w, t}$. The descriptive statistics for IROE and IVROE are reported in Panel B of Table 2.

The equally weighted average IROEs are all negative except in the first five-year period. That means that, on average, firms' ROEs decline. But the magnitude is much smaller than that in Panel A. The value-weighted average IROEs, however, become more visibly positive in the last ten-year period, implying an upward trend. These patterns are qualitatively consistent with what the results reported in Panel A. The important differences are in their magnitude. The smaller magnitude of IROEs indicates that much of the contracting of earnings occurs when new stocks are listed in the market.

The equally weighted and value-weighted average IVROEs show little or no trend at all. They are close to zero most of the time. The upward trends in the average VROEs in Panel A are due to the newly listed firms. 


\section{G. Other Variables}

In Panel $\mathrm{C}$ of Table 2 we also report simple descriptive statistics of other variables that will be used in our analysis. SZ is the log of firm equity size (in million dollars) that has played important role in the analysis of expected return and volatility of returns. AGE is the firm age defined as the log of the number of years a firm has been in the CRSP as a proxy for how long the firm has been listed for trading. Pástor and Veronesi (2002) argue that younger firms tend to be in more growth oriented industries and have greater uncertainty about their future growth, and hence have greater return volatility. LV is the firm leverage defined as the ratio of long-term debt to total assets. Other things being equal, more highly levered firms are supposed to have higher bankruptcy risk and hence higher return volatility. BM is the log of the book-to-market equity ratio which is found to have explanatory power for the expected returns by the work of Fama and French (1992). Its role with the risk of returns, however, has been controversial. See Lakonishok et al (1994).

Both equally weighted averages and value-weighted averages of the variables are reported. Averages of firm size show a slight upward trend as firms grow, despite more small firms enter the market every year. The averages of log(firm age) ranges from 2.29 to 3.02 that translates to about 10 to 20 years. No significant trend can be spotted. The averages of firm leverage ratio exhibit a small downward trend. BM is high in the recessions of the 1970 s.

\section{H. Graphical Analysis of ROE and VROE}

Figure 2 plots the time-series of the equally weighted and value-weighted averages of ROE and IROE. The top panel is for equally weighted averages. The thin line representing the average ROE shows an obvious downward trend. The heavy line for the average incremental ROE declines in the early 1980s and drifts around afterwards without following an obvious trend. In the figure, the difference between the two lines narrows in 
the 1986-2000 period, indicating that it is mainly the newly listed stocks that contribute to the declining average ROE.

\section{Figure 2 here}

The value-weighted average ROE represented by the thin line in the bottom panel exhibits a different upward trend. Unlike for small firms, the profitability of large firms improves on average. The heavy line of the value-weighted average of incremental ROEs moves parallel with the thin line, showing no effects of newly listed large stocks on the average ROE.

Figure 3 is the time-series plot of the equally weighted and value-weighted averages of VROE and IVROE. In the top panel, the equally weighted average of VROE represented by the thin line shows an upward trend beginning in the early 1980s. The heavy line for the average incremental VROE increases slightly in the first half of the sample period, decreases in the second half, and ends in the negative region. The pattern gives a clear indication that the rise in the ROE volatility is caused by the newly listed firms.

\section{Figure 3 here}

The bottom panel of Figure 3 for value-weighted averages of VROE and IVROE also reveals an interesting pattern. Unlike the case of $\mathrm{ROE}$, the ROE volatility of large firms grows worse, especially in the last five-year period. The heavy line of the incremental VROE again shows that most of the increase in ROE volatility comes from the newly listed firms.

\section{Cross-sectional Regression Results}

The preliminary analysis in the last section has shown that, as the average variance of stock returns increases over time, the average return-on-equity declines and the average 
variance of return-on-equity goes up. While our main purpose of the paper is to analyze the volatility trend over time, in order to demonstrate that the time-series relationships we analyze are not spurious ones, we perform cross-sectional analysis first in this section. In particular, we demonstrate that the cross-sectional relationship between the return volatility and the two fundamental variables related to earnings is a robust one. Other variables are also important in the cross-sectional relations, but for the reason given in the next section, we place less emphasis on them.

\section{A. Cross-sectional Analysis of Variance of Returns}

Before we present cross-sectional regression analysis on the relation among return variances, return-on-equity and its variance, we first present figures to give visual impressions. The top panel of Figure 4 shows the bivariate cross-sectional relations between return variance and return-on-equity over time and the bottom panel of Figure 4 shows the bivariate cross-sectional relations between return variance and the variance of returnon-equity over time.

Figure 4 here

The top panel of Figure 4 is constructed as follows. For each month $t$, stocks are sorted according to their ROE and then divided into five groups. Quintile 1 includes stocks that have the lowest ROE while Quintile 5 comprises stocks that have the highest ROE. The simple average of the return variances is then calculated for each quintile at each $t$. Only the average return variances for Quintiles 1,3 and 5 are plotted in the figure. The other two are omitted to avoid clustering. As we can see, return variance and return-on-equity are cross-sectionally negatively associated. The average return variance of Quintile 1 (with the lowest ROE) is the highest at all times. The relation, however, is not monotonic among other quintiles. Quintiles 3 and 5 have their average variances mixed and, for most of the time, the average return variance is actually slightly lower 
for Quintile 3 than that for Quintile 5.

The bottom panel of Figure 4 is constructed similarly using VROE to sort stocks. Quintile 1 has stocks that have the lowest VROE while Quintile 5 has stocks that have the highest VROE. The simple average of return variances is then calculated for each quintile for each month $t$. The average return variances for Quintiles 1,3 and 5 are plotted. The relation between the variance of returns and the variance of return-onequity is a positive one. The average variance for Quintile 5 is the highest, that for Quintile 1 is the lowest, and that for Quintile 3 is in the middle. The relationship is much clearer than that between the return variance and return-on-equity.

We now turn to the cross-sectional regression analysis of the variances of returns. We only report the result for raw returns here, because the cross-sectional difference between the volatilities of raw returns and market-adjusted returns are very small. For each month $t$ in the 1976-2000 period, we estimate coefficients in the following regression,

$$
\begin{aligned}
\mathrm{VR}_{i t}^{\text {raw }}= & \phi_{1}+\phi_{2} \mathrm{ROE}_{i, t-1}+\phi_{3} \mathrm{VROE}_{i, t-1}+\phi_{4} \mathrm{VR}_{i, t-1}^{\text {raw }}+\phi_{5} R_{t} \\
& +\phi_{6} \mathrm{AGE}_{i, t}+\phi_{7} \mathrm{SZ}_{i, t-1}+\phi_{8} \mathrm{LV}_{i, t-1}+\phi_{9} \mathrm{BM}_{i, t-1}+\varepsilon_{i t}
\end{aligned}
$$

where $R_{t}$ is the contemporaneous return in month $t$ and $\mathrm{VR}_{i, t-1}^{r a w}$ is the lagged value of the return volatility. Return volatility is known to be autocorrelated. The use of contemporaneous return in the regression is advocated by Duffee (1995) based on the notion that expected return and risk are positively related, so their realizations have a common component. These two variables, $\mathrm{VR}_{i, t-1}^{r a w}$ and $R_{t}$, are used here as control variables to assess whether other variables have additional explanatory power. The estimated coefficients for all the months are then averaged over time to obtain the final estimate of the parameter as in standard cross-sectional regressions. Since return volatility is autocorrelated and heteroskedastic, the monthly estimates inherit these statistic properties too. The t-ratios reported in the parentheses are adjusted for autocorrelation and conditional heteroskedasticity. We also run regressions using $\mathrm{ROE}_{i, t-1}$ and $\mathrm{VROE}_{i, t-1}$ alone or together. The results for each five-year subperiod as well as for the entire sample period 
of 1976-2000 are reported in Table 3.

Table 3 here

We first discuss the explanatory power of ROE and VROE. The estimates of the slope coefficients of ROE and VROE confirm what we have seen from Figure 4. The variance of returns is negatively associated with return-on-equity and the negative relation is significant. The relation between the variance of returns and the variance of returnon-equity is significantly positive. The return-on-equity and its variance are negatively correlated. When the regression includes both of them as independent variables, the estimates of the slope coefficients are somewhat reduced, but remain strongly significant. Pástor and Veronesi (2002) contain a cross-sectional analysis of return volatility with many firm-specific variables including ROE and a measure of ROE volatility. Their measure of ROE volatility, however, is an estimate of unconditional volatility for each stock, different from the conditional measure VROE we use here.

Of other variables used in the regression in addition to ROE and VROE, all have significant coefficients for the entire period except for the leverage LV. The coefficients of the contemporaneous return and firm size appear to be very significant with correct signs and they are also stable across subperiods. The lagged return volatility does not have strong explanatory power when combined with other variables. Firm age has a positive coefficient for the first subperiod and weak coefficients for the last two subperiods, making its overall explanatory power less important for the entire period. Leverage does not have stable and significant relation with return volatility. Overall, $\mathrm{BM}$ is positively related to the return volatility, consistent with its positive relation with expected returns. In the first two five-year subperiods, however, its sign in the return volatility regressions is negative. One observation that is worth pointing out is that the role of ROE and VROE is somewhat reduced when combined with the other variables, although their coefficients remain very significant. 


\section{B. Cross-sectional Analysis of Incremental Variance of Returns}

To associate return volatility with return-on-equity and its variance more closely, we run the cross-sectional regression of IVR on IROE and IVROE at the firm level,

$$
\begin{aligned}
\operatorname{IVR}_{i t}^{\text {raw }}= & \phi_{1}+\phi_{2} \mathrm{IROE}_{i, t-1}+\phi_{3} \mathrm{IVROE}_{i, t-1}+\phi_{4} \mathrm{IVR}_{i, t-1}^{\text {raw }}+\phi_{5} R_{t} \\
& +\phi_{6} \mathrm{AGE}_{i, t}+\phi_{7} \mathrm{SZ}_{i, t-1}+\phi_{8} \mathrm{LV}_{i, t-1}+\phi_{9} \mathrm{BM}_{i, t-1}+\varepsilon_{i t},
\end{aligned}
$$

The estimated coefficients for all the months are then averaged over time and t-statistics are calculated as before. The results are reported in Table 4.

Table 4 here

As we can see in Table 4, incremental return volatility is also negatively related to incremental return-on-equity, IROE, and positively related to incremental variance of return-on-equity, IVROE. The slope coefficients are significant at conventional significance levels in the entire sample period and in all the subperiods. As expected, however, the t-ratios for all of the regressions with the incremental variables are smaller than those in Table 3. Since return volatility is not exclusively caused by return-on-equity and its variance, incremental return volatility is explained less by incremental return-on-equity and its variance. For variables other than IROE and IVROE, the contemporaneous return and the lagged return volatility have the most significant role. Other variables do have stable relations with return volatility. IROE and IVROE continue to have significant role when used in combination with the other variables, except for the first subperiod in which IVROE loses its explanatory power. 


\section{Trend Analysis}

\section{A. Time-series Analysis of Variance of Returns}

Having established the cross-sectional relations of return variances with the two firmspecific variables, ROE and VROE, and other variables, we now turn to the main issue of the upward trend in the averages of the return variances. We will use the averages of the firm-specific variables to explain the trend in average return volatility. Having timeseries explanatory power is a different matter with having cross-sectional explanatory power. To be useful in explaining the trend in return volatility, an aggregate variable has to be in one of the following two situations. Either the variable has an upward trend and, when detrended, has a positive correlation with the detrended return volatility, or the variable has a downward trend and, when detrended, has a negative correlation with the detrended return volatility. We will show below that, by and large, ROE fits the first case and VROE fits the second case. Other variables, however, do not fit these descriptions and therefore they are incapable of explaining return volatilities and will not be discussed in the rest of this section. ${ }^{7}$ In time-series analysis, however, we add another variable as an explanatory variable: the cross-sectional (equally weighted) sample variance of ROEs, denoted CVROE. ${ }^{8}$ It differs from VROE in that it measures the deviation from the cross-sectional average of ROE and in that it only relies on the current ROEs while VROE depends on ROEs of the past three years. In the analysis of the incremental return volatility, we have ICVROE accordingly.

Over the period of 1976-2000, the average return-on-equity declined, and the variance of return-on-equity increased substantially, the trend in these two variables may have contributed to the increase in the average return volatility. To establish such a link, we

\footnotetext{
${ }^{7}$ For example, detrended equally weighted average size has a detrended correlation of -0.24397 with $\mathrm{VR}_{e w, t}^{\text {raw }}$, but average size has an upward trend as can be seen from Table 2. Similarly, detrended average firm age has a correlation of -0.31026 with $\mathrm{VR}_{e w, t}^{r a w}$, but its trend is so obscure that it does not contribute significantly in explaining the trend in return volatilities.

${ }^{8}$ We thank the referee for suggesting this variable.
} 
run regressions of the following type,

$$
\mathrm{VR}_{t}=\theta_{0}+\theta_{1} t+\theta_{2} \mathrm{ROE}_{t-1}+\theta_{3} \mathrm{VROE}_{t-1}+\theta_{4} \mathrm{CVROE}_{t-1}+\varepsilon_{t}
$$

where $\mathrm{VR}_{t}, \mathrm{ROE}_{t-1}$, and $\mathrm{VROE}_{t-1}$ are either all value-weighted or all equally weighted. In addition, $\mathrm{VR}_{t}$ can be either the average variance of raw returns or of market-adjusted returns. Of three explanatory variables on the right-hand side of the equation, combinations of them are used to separate their contributions in explaining the variation in the average return variance over time. The results are reported in Table 5.

\section{Table 5 here}

Panel A is for $\mathrm{VR}_{e w, t}^{r a w}$. The first regression uses the time trend only as the explanatory variable. The slope coefficient, when multiplied by 100,000, is 16.3413 with an Generalized Method of Moments (GMM)-based t-ratio 10.6384. As we noted earlier, the regression error terms are likely to be autocorrelated with conditional heteroskedasticity. The GMM-based t-ratio uses the Newey-West type of adjustment for autocorrelation and conditional heteroskedasticity and is typically in this study half of the OLS t-ratio value. The regression result adds to the evidence presented in Table 1 by giving an estimate of the monthly increment in the equally weighted average variance of returns. The monthly increment in return volatility is significantly greater than zero and greater than that reported by Campbell et al (2001) due to the extremely high return volatility in the last few years not covered by their study.

The next three regressions look at how the equally weighted averages of ROE, VROE, and CVROE contribute to explaining the equally weighted average variance of returns. When time and $\mathrm{ROE}_{e w, t-1}$ are used to explain the variation in $\mathrm{VR}_{e w, t}^{\text {raw }}$, the slope coefficient of $\mathrm{ROE}_{e w, t-1}, \theta_{2}$, is negative and significant, as we have seen in the cross-sectional regressions. The coefficient for the time trend is more than halved at 6.6187 with the GMM t-ratio reduced by $4 / 5$. Although the trend coefficient is still marginally significantly greater than zero, it is obvious that more than half of the upward trend in the 
equally weighted average variance of returns is explained by the downward trend in the equally weighted average ROE. The regression using time and $\mathrm{VROE}_{e w, t-1}$ tells a more compelling story. The slope coefficient of $\mathrm{VROE}_{e w, t-1}$ is positive and significant, as in the cross-sectional regressions. That helps reduce the trend coefficient $\theta_{1}$ by three quarters and renders its t-ratios insignificant. The role of $\mathrm{CVROE}_{e w, t-1}$ is very similar to that of $\mathrm{VROE}_{e w, t-1}$. When both $\mathrm{ROE}_{e w, t-1}$ and $\mathrm{VROE}_{e w, t-1}$ are used to explain the return variance, their significance is reduced compared with the cases when they are used individually because the two variables are correlated. The trend coefficient, $\theta_{1}$, is near zero and the GMM t-ratio indicate that the trend coefficient is not significantly different from zero. The evidence here shows that most of the upward trend in the equally weighted average variance of returns can be explained by the downward trend in the equally weighted average return-on-equity and the upward trend in the equally weighted average variance of return-on-equity. When all three explanatory variables are used, multi-collinearity makes them all insignificant while the trend coefficient is slightly negative.

The results for the equally weighted average variances of market-adjusted returns are presented in Panel B. The results are qualitatively the same as those for raw returns. Adding $\mathrm{ROE}_{e w, t-1}$ and $\mathrm{VROE}_{e w, t-1}$ to the regression substantially reduces the trend coefficient, $\theta_{1}$, of the return variance and render it insignificantly different from zero.

Panel $\mathrm{C}$ of Table 5 reports the results for value-weighted averages. We know from Table 1 that, although the value-weighted average variance in 1996-2000 is about three times that in 1976-1980, the major increase occurs in the 1996-2000 period. This is reflected in the estimation of the trend coefficient that treats each month in the sample period equally. The trend coefficient is only 3.4547 per month when multiplied by 100,000, less than a quarter of the magnitude of the equally weighted average. When $\mathrm{ROE}_{v w, t-1}$ is added to the regression, the trend coefficient (multiplied by 100,000) is reduced to 2.6475 . A seeming puzzle is that the slope coefficient of $\mathrm{ROE}_{v w, t-1}$ is positive, opposite to those 
in cross-sectional regressions and in the regression with $\mathrm{ROE}_{e w, t-1}$. One explanation for this will be provided later. The regression using time and $\mathrm{VROE}_{v w, t-1}$ as explanatory variables has a striking result. The estimated slope coefficient of $\mathrm{VROE}_{v w, t-1}$ is large and strongly significant. The increment in $R^{2}$ is also very large. The presence of $\operatorname{VROE}_{v w, t-1}$ makes the trend coefficient significantly negative. That means, after controlling the level of $\mathrm{VROE}_{v w, t-1}$, the value-weighted average variance of returns actually declines over time. $\mathrm{CVROE}_{v w, t-1}$ is not very useful in explaining the value-weighted average return volatility, alone or with other variables. The estimated slope coefficient of $\mathrm{ROE}_{v w, t-1}$ in the regression using time, $\mathrm{ROE}_{v w, t-1}$ and $\mathrm{VROE}_{v w, t-1}$ as explanatory variables is insignificant, though still positive. This gives a clue to why, in the regression using time and $\mathrm{ROE}_{v w, t-1}$ as explanatory variables, the coefficient of $\mathrm{ROE}_{v w, t-1}$ is significantly positive. Unlike the correlation between the detrended $\mathrm{ROE}_{e w, t-1}$ and the detrended $\mathrm{VROE}_{e w, t-1}$, which is negative, the correlation between the detrended $\mathrm{ROE}_{v w, t-1}$ and the detrended $\mathrm{VROE}_{v w, t-1}$ is positive. ${ }^{9}$ The positive slope coefficient of $\mathrm{ROE}_{v w, t-1}$ is carried over from the positive coefficient of $\operatorname{VROE}_{v w, t-1}$, which is strong but missing from the regression. In Panel D, the regressions of the value-weighted average of the market-adjusted returns have very similar results as those of the raw returns. $\mathrm{VROE}_{v w, t-1}$ plays a major role in explaining the trend in the return variance and makes the estimate of the trend coefficient negative.

\section{B. Time-series Analysis of Incremental Variance of Returns}

From Figure 1, we know that the equally weighted average of the incremental variance of returns is near zero for the first half of the sample and is mostly positive in the second half of the sample. An upward trend can still be drawn that reflects the increase in the return volatility for existing firms. How this increase can be explained by the changes in

\footnotetext{
${ }^{9}$ Recall from Tables II, Figure 2 and Figure 3 that $\mathrm{ROE}_{e w, t}$ has a downward trend while $\mathrm{VROE}_{e w, t}$ has an upward trend. Both $\mathrm{ROE}_{v w, t}$ and $\mathrm{VROE}_{v w, t}$, however, have upward trends. After trends are removed from these time series, the correlation between $\mathrm{ROE}_{e w, t}$ and $\mathrm{VROE}_{e w, t}$ is -0.32 while the correlation between $\mathrm{ROE}_{v w, t}$ and $\mathrm{VROE}_{v w, t}$ is 0.30 .
} 
the average ROE and average VROE is the subject of this subsection. Table 6 presents the results of the regressions of the form

$$
\mathrm{IVR}_{t}=\theta_{0}+\theta_{1} t+\theta_{2} \mathrm{IROE}_{t-1}+\theta_{3} \mathrm{IVROE}_{t-1}+\theta_{4} \mathrm{ICVROE}_{t-1}+\varepsilon_{t},
$$

where $\operatorname{IVR}_{t}, \mathrm{IROE}_{t-1}$, and $\operatorname{IVROE}_{t-1}$ are either all value-weighted or all equally weighted. In addition, $\mathrm{IVR}_{t}$ can be either the average variance of the raw returns or of the marketadjusted returns.

\section{Table 6 here}

Panel A of Table 6 reports the estimated coefficients for the equally weighted average variables. The first regression shows that the upward trend in the average incremental variance is still there, but it is much less than the one in the variance itself. Inclusion of $\mathrm{IROE}_{e w, t-1}$ reduces the magnitude of the trend coefficient and its significance slightly. But the trend coefficient remains significantly positive. $\operatorname{IVROE}_{e w, t-1}$ does not have explanatory power. This can be understood because, from Figure 3, we know that IVROE $_{e w, t-1}$ does not have much variation. Surprisingly, the $\mathrm{ICVROE}_{e w, t-1}$ effect is strong and it brings the trend coefficient strongly negative. Panel B contains the results for the equally weighted average of the incremental variance of the market-adjusted returns that are very similar to the ones in Panel A.

The value-weighted averages of the incremental variance of returns are very close to zero most of the time and do not contain an upward trend except for the last three years in the sample, as we see from Figure 1. Nevertheless, for completeness, we perform the same regressions and report the results in Panels $\mathrm{C}$ and $\mathrm{D}$ of Table 6 . As we expect, the trend coefficient, $\theta_{1}$, is insignificant to begin with, after autocorrelation and heteroskedasticity are corrected for. The slope coefficients of the explanatory variables are insignificant throughout. 


\section{Discussion}

We have demonstrated that the upward trend of the average return volatility of stocks is strongly associated with changes in fundamentals. We show that two fundamental variables, ROE and VROE, have changed dramatically over our sample period and have caused stock returns to be more volatile over time. Fundamental variables other than the two we tried in this paper may also have effects on the cross-sectional distribution of the return volatility. These variables include the firm-level financial leverage, the firm size, the book-to-market ratio, and so on. However, we do not find significant relationships between the average stock return volatility and the average leverage, the average firm size, or the average book-to-market ratio in the time-series. Our findings are consistent with the remarks by Campbell et al (2001) that financial leverage is not the cause of the upward trend in the average stock return volatility and by Schwert (1989) that aggregate leverage is not responsible for the extremely high return volatility in the 1929-1933 Great Depression.

Why the fundamentals change over time is beyond the scope of this paper. The following is a brief discussion of our results in relation to the recent literature. Fama and French (2001) study the earnings for newly listed stocks. They point out that "there is a change in the market for new lists around 1980, allowing firms to list earlier in their life cycles, when they are smaller, growing rapidly, but still relatively unprofitable." In particular, they find that after 1981, newly listed firms become progressively less profitable and the newly listed firms that survive remain less profitable than all listed firms. What we show in this paper is that the return volatility of the newly listed stocks is the main culprit for the increasing average return volatility for all firms. Schwert (2001) analyzes the return volatility for NASDAQ stocks in about the same sample period as we have and pays special attention to the last few years of the sample. His finding that many NASDAQ firms located in high-tech industries with growth options explains why these firms have higher earnings volatility and hence higher return volatility. The 
analytical and empirical results in Pástor and Veronesi (2002) also shed light on the issue.

\section{Concluding Remarks}

In this paper we address the issue of increasing average volatility in stock returns, previously documented by Campbell et al (2001) and Morck et al (2000). We find that two variables, the average return-on-equity and the average sample variance of the return-onequity are useful in explaining the upward trend in the average stock return variances. Over the period of 1976-2000, the average return-on-equity declined while the average sample variance of return-on-equity increased. The upward trend in the averages of return variance is explained by the two variables. This is true for both variances of raw returns and market-adjusted returns. These two variables are also significantly related to the return variance in cross-section at the firm level. While firm size and firm age also can explain much of the cross-sectional differences in return variances, they are not responsible for the upward trend over time.

We explore the sources of increasing stock return volatility. The components of the stock market change over time; some firms exit from the stock market while some more enter. It is interesting to know whether the average stock return volatility increases mainly because the volatility of each stock rises on average, or because newcomers tend to have higher volatility. Our conclusion is that the latter is the main reason for the increasing average return volatility and the cause of it is the worsening profitability of the newly listed firms. While existing firms, especially the smaller ones, also exhibit an upward trend in return volatility, the pattern is less clear and the magnitude is small.

The contribution of the results obtained in this paper can be evaluated from the perspective of the larger literature on the so-called excess volatility of stock returns. Opinions about high return volatility can be roughly classified into three strands. The 
first group argues that high return volatility is excessive in the sense that the return volatility is too high to be explained by the changes in the fundamental variables. Shiller (1981) is representative of this view. The second group believes that stock return volatility is caused by changes in the fundamental variables and high volatility is undesirable. This has been the mainstream view in asset pricing studies. The third group posits that stock return volatility is caused by changes in fundamental variables, but regards a higher ratio of the firm-specific volatility to the volatility in the market portfolio as a desirable property, indicating more firm-specific information is captured by stock prices.

The evidence presented in this paper lends support to the second view mentioned above. The upward trend in the average stock return volatility is found to be mainly caused by newly listed firms that are smaller in size with lower current and past earnings and higher earnings volatility. The upward trend in return volatility may reverse its course once corporate earnings are improved and its uncertainty is reduced. A recent paper by Fama and French (2001) points out that there has been a sharp increase of new firms listing in the major U.S. stock exchanges and a declining trend of profitability of the newly listed firms after 1979. Their evidence is consistent with ours and provides further support for our view.

The main message from this paper is that the upward trend in the average return volatility is caused by changes in the fundamental variables, but we say little about whether there is or is not excessive volatility in individual return volatilities. While return volatility at the firm level is strongly related to earnings and earnings volatility cross-sectionally, it is far from being fully explained by these two variables.

The increased average return volatility in the period 1976-2000 is mainly attributed to the declining earnings and rising earnings volatility, so this increase in return volatility is undesirable based on this evidence. Whether stock prices have become more informative is not tested here directly, so we do not interpret the evidence here as opposite to the argument presented by Morck et al (2000). However, since the increased return 
volatility mainly comes from newly listed firms and existing large firms do not experience significant increases in return volatility, the information-based theory is perhaps not the most important explanation of why individual stocks became more volatile. 


\section{References}

Campbell, J., and R. S. 1988. The dividend-price ratio and expectations of future dividends and discount factors, Review of Financial Studies 1: 195-227.

Campbell, J.Y.; Lettau, M.; Malkiel. B. G.; and Xu, Y. 2001. Have individual stocks become more volatile? An empirical exploration of idiosyncratic risk, Journal of Finance 56: 1-43.

Cochrane, J. 1992. Explaining the variance of price-dividend ratios. Review of Financial Studies 5: 243-280.

Duffee, G. 1995. Stock returns and volatility: a firm-level analysis, Journal of Financial Economics 37: 399-420.

Durnev, A.; Morck, R.; and Young, B. 2000. Does firm-specific information in stock prices guide capital allocation? Working Paper.

Durnev, A.; Morck, R.; Young, B.; and Zarowin, P. 2001. Does greater firm-specific return variation mean more or less informed stock pricing? Working Paper.

Fama, E., and MacBeth, J. 1973. Risk, return and equilibrium: Empirical tests, Journal of Political Economy 81: 607-636.

Fama, E., and French, K. 2001. Newly listed firms: Fundamentals, survival rates, and returns Working Paper, University of Chicago.

Lintner, J. 1956. Distribution of incomes of corporations among dividends, retained earnings, and taxes, American Economic Review 66: 97-113.

Malkiel, B. G., and Xu, Y. 2002. Investigating the behavior of idiosyncratic volatility, Journal of Business, forthcoming. 
Marsh, T., and Merton, R. C. 1986. Dividend variability and variance bounds tests for the rationality of stock market prices, American Economic Review 76: 483-498.

Morck, R.; Yeung, B.; and Yu, W. 2000. The information content of stock markets: Why do emerging markets have synchronous stock price movements? Journal of Financial Economics 58: 215-260.

Pástor, Ľ and Veronesi, P. 2002. Stock valuation and learning about profitability, Journal of Finance, forthcoming.

Roll, R. 1988. $R^{2}$, Journal of Finance 43: 541-566.

Schwert, G. W. 1989. Why does stock market volatility change over time? Journal of Finance 44: 1115-1153.

Schwert, G. W. 2001: Stock volatility in the new millennium: How wacky is NASDAQ? Working Paper, William E. Simon Graduate School of Business Administration, University of Rochester.

Shiller, R. J. 1981. Do stock price move too much to be justified by subsequent changes in dividends? American Economic Review 71: 421-436.

Vuolteenaho, T. 2002. What drives firm-level stock returns? Journal of Finance 57: 233-264. 
Table 1 Descriptive Statistics of Variance of Returns (VR)

\begin{tabular}{|c|c|c|c|c|c|}
\hline \multicolumn{6}{|c|}{ A: Variance of returns } \\
\hline Subperiod & $1976-1980$ & $1981-1985$ & $1986-1990$ & 1991-1995 & $1996-2000$ \\
\hline \# stocks & 2150.25 & 2172.98 & 3213.25 & 3799.07 & 4862.27 \\
\hline $\mathrm{VR}_{e w, t}^{r a w}$ & 18.82 & 17.09 & 37.80 & 52.47 & 60.09 \\
\hline $\mathrm{VR}_{e w, t}^{a d j}$ & 17.96 & 16.44 & 37.01 & 52.19 & 59.94 \\
\hline $\mathrm{VR}_{v w, t}^{r a w}$ & 6.75 & 8.51 & 10.13 & 8.23 & 19.49 \\
\hline $\mathrm{VR}_{v w, t}^{a d j}$ & 5.40 & 6.90 & 7.12 & 7.33 & 15.94 \\
\hline \multicolumn{6}{|c|}{ B: Incremental variance of returns } \\
\hline Subperiod & $1976-1980$ & $1981-1985$ & $1986-1990$ & 1991-1995 & $1996-2000$ \\
\hline \# stocks & 2143.27 & 2156.83 & 3105.52 & 3640.65 & 4512.57 \\
\hline $\operatorname{IVR}_{e w, t}^{r a w}$ & -1.46 & -2.95 & 9.56 & 14.00 & 13.80 \\
\hline $\mathrm{IVR}_{\text {ew }, t}^{a d j}$ & -0.43 & -1.70 & 10.82 & 16.34 & 17.34 \\
\hline $\mathrm{IVR}_{v w, t}^{r a w}$ & 0.62 & 1.20 & 2.12 & -1.20 & 6.62 \\
\hline $\operatorname{IVR}_{v w, t}^{a d j}$ & 0.72 & 1.23 & 0.92 & -0.22 & 5.74 \\
\hline
\end{tabular}

Note.-Panel A of the table presents time-series means of the equally weighted and value-weighted averages of variance of the raw returns, $\mathrm{VR}_{e w, t}^{r a w}$ and $\mathrm{VR}_{v w, t}^{r a w}$, and the equally weighted and valueweighted averages of variance of the market-adjusted returns, $\mathrm{VR}_{e w, t}^{a d j}$ and $\mathrm{VR}_{v w, t}^{a d j}$, in subperiods of 1976-2000. Panel B of the table presents time-series means of the equally weighted and value-weighted averages of the incremental variance of the raw returns, $\mathrm{IVR}_{e w, t}^{r a w}$ and $\mathrm{IVR}_{v w, t}^{r a w}$, and the equally weighted and value-weighted averages of the incremental variance of the market-adjusted returns, IVR ${ }_{e w, t}^{a d j}$ and $\mathrm{IVR}_{v w, t}^{a d j}$, in subperiods of 1976-2000. Returns used in the calculations are monthly data and all the variances are multiplied by 1200 . 
Table 2 Descriptive Statistics for ROE, VROE and Other Explanatory Variables

A: ROE and VROE

\begin{tabular}{lccccc} 
Subperiod & $1976-1980$ & $1981-1985$ & $1986-1990$ & $1991-1995$ & $1996-2000$ \\
ROE $_{e w, t}$ & 9.73 & 6.78 & 3.37 & 2.07 & 0.30 \\
ROE $_{v w, t}$ & 13.19 & 11.75 & 12.22 & 13.02 & 16.20 \\
VROE $_{e w, t}$ & 0.64 & 0.89 & 1.99 & 2.54 & 2.61 \\
VROE $_{v w, t}$ & 0.13 & 0.25 & 0.52 & 0.72 & 1.07 \\
B: IROE and IVROE & & & & \\
Subperiod & $1976-1980$ & $1981-1985$ & $1986-1990$ & $1991-1995$ & $1996-2000$ \\
IROE $_{e w, t}$ & 0.93 & -3.08 & -4.48 & -4.90 & -3.09 \\
IROE $_{v w, t}$ & 1.37 & -0.89 & -0.21 & 0.70 & 4.21 \\
IVROE $_{e w, t}$ & -0.01 & 0.12 & 0.38 & 0.17 & -0.20 \\
IVROE $_{v w, t}$ & 0.00 & 0.04 & 0.20 & 0.12 & 0.01 \\
$\mathrm{C} \mathrm{AGE}, \mathrm{SZ}, \mathrm{LV}$ & and BM & & & & \\
$\mathrm{Subperiod}$ & $1976-1980$ & $1981-1985$ & $1986-1990$ & $1991-1995$ & $1996-2000$ \\
$\mathrm{SZ}_{e w, t}$ & 4.48 & 4.85 & 4.64 & 4.82 & 5.22 \\
$\mathrm{SZ}_{v w, t}$ & 7.37 & 7.85 & 8.36 & 8.78 & 9.83 \\
$\mathrm{AGE}_{e w, t}$ & 2.36 & 2.59 & 2.38 & 2.39 & 2.29 \\
$\mathrm{AGE}_{v w, t}$ & 2.62 & 2.83 & 2.93 & 3.02 & 2.97 \\
$\mathrm{LV}_{e w, t}$ & 0.23 & 0.19 & 0.19 & 0.17 & 0.18 \\
$\mathrm{LV}_{v w, t}$ & 0.21 & 0.17 & 0.18 & 0.18 & 0.16 \\
$\mathrm{BM}_{e w, t}$ & 0.04 & -0.22 & -0.50 & -0.61 & -0.73 \\
$\mathrm{BM}_{v w, t}$ & -0.22 & -0.37 & -0.75 & -1.01 & -1.55 \\
\hline & & & & & \\
\hline
\end{tabular}

Note.-Panel A of the table presents the time-series means of the equally weighted and value-weighted averages of return-on-equity, $\mathrm{ROE}_{e w, t}$ and $\mathrm{ROE}_{v w, t}$, and the equally weighted and value-weighted averages of the sample variance of return-on-equity, $\mathrm{VROE}_{e w, t}$ and $\mathrm{VROE}_{v w, t}$, in subperiods of 1976-2000. Panel B of the table presents the time-series means of the equally weighted and value-weighted averages of incremental return-on-equity, $\mathrm{IROE}_{e w, t}$ and $\mathrm{IROE}_{v w, t}$, and the equally weighted and value-weighted averages of the incremental sample variance of return-on-equity, $\mathrm{IVROE}_{e w, t}$ and $\mathrm{IVROE}_{v w, t}$, in subperiods of 1976-2000. Earnings used in the calculations are quarterly data and the numbers are multiplied by 400. Panel $\mathrm{C}$ lists equally weighted and value-weighted average log of firm equity size (SZ), firm age (AGE), leverage (LV) defined as the ratio of long-term debt to total assets, and the log of book-to-market equity ratio $(\mathrm{BM})$. 
Table 3 Cross-sectional Regression of VR on ROE, VROE and Other Variables

\begin{tabular}{|c|c|c|c|c|c|c|c|c|c|}
\hline Period & $\phi_{1}$ & $\phi_{2}$ & $\phi_{3}$ & $\phi_{4}$ & $\phi_{5}$ & $\phi_{6}$ & $\phi_{7}$ & $\phi_{8}$ & $\phi_{9}$ \\
\hline \multirow[t]{7}{*}{$\begin{array}{l}1976.01 \\
-2000.12\end{array}$} & $\begin{array}{c}0.0320 \\
(15.95)\end{array}$ & $\begin{array}{l}-0.1795 \\
(-15.19)\end{array}$ & & & & & & & \\
\hline & 0.0244 & & 1.2832 & & & & & & \\
\hline & ( 15.21$)$ & & ( 21.91) & & & & & & \\
\hline & 0.0273 & -0.1624 & 1.0721 & & & & & & \\
\hline & $(16.41)$ & $(-15.15)$ & $(23.13)$ & & & & & & \\
\hline & 0.0311 & -0.0850 & 0.4093 & 0.4384 & 19.7212 & -0.0560 & -0.3930 & -0.0602 & 0.1340 \\
\hline & $(10.52)$ & $(-14.08)$ & ( 14.94) & ( 25.07) & ( 8.30$)$ & $(-1.96)$ & $(-12.04)$ & $(-0.45)$ & $(2.22)$ \\
\hline \multirow{7}{*}{$\begin{array}{l}1976.01 \\
-1980.12\end{array}$} & 0.0153 & -0.0782 & & & & & & & \\
\hline & $(11.30)$ & $(-6.91)$ & & & & & & & \\
\hline & 0.0113 & & 1.0988 & & & & & & \\
\hline & ( 10.39) & & ( 17.45$)$ & & & & & & \\
\hline & $\begin{array}{c}0.0138 \\
(11.30)\end{array}$ & $\begin{array}{r}-0.0742 \\
(-8.58)\end{array}$ & $\begin{array}{c}1.0406 \\
(15.21)\end{array}$ & & & & & & \\
\hline & 0.0117 & -0.0419 & 0.3961 & 0.4110 & 6.4684 & 0.1523 & -0.2118 & 0.0982 & -0.1402 \\
\hline & ( 9.87$)$ & $(-6.39)$ & ( 7.63) & $(12.38)$ & ( 6.94$)$ & $(9.12)$ & $(-8.62)$ & $(0.95)$ & $(-2.75)$ \\
\hline \multirow{8}{*}{$\begin{array}{l}1981.01 \\
-1985.12\end{array}$} & 0.0164 & -0.1055 & & & & & & & \\
\hline & $(27.34)$ & $(-12.25)$ & & & & & & & \\
\hline & 0.0121 & & 0.9261 & & & & & & \\
\hline & $(20.83)$ & & $(15.62)$ & & & & & & \\
\hline & 0.0146 & -0.0912 & 0.7472 & & & & & & \\
\hline & $(24.17)$ & $(-11.49)$ & $(16.98)$ & & & & & & \\
\hline & 0.0161 & -0.0554 & 0.3416 & 0.3961 & 6.4174 & -0.0808 & -0.1626 & 0.3999 & -0.1140 \\
\hline & ( 14.74) & $(-8.22)$ & ( 6.79$)$ & (14.33) & $(5.22)$ & $(-2.61)$ & $(-11.24)$ & ( 3.75$)$ & $(-2.43)$ \\
\hline \multirow{8}{*}{$\begin{array}{l}1986.01 \\
-1990.12\end{array}$} & 0.0333 & -0.1984 & & & & & & & \\
\hline & ( 9.49) & $(-7.76)$ & & & & & & & \\
\hline & 0.0252 & & 1.2243 & & & & & & \\
\hline & ( 9.19) & & $(9.29)$ & & & & & & \\
\hline & 0.0285 & -0.1814 & 1.0316 & & & & & & \\
\hline & ( 9.35) & $(-7.54)$ & $(9.21)$ & & & & & & \\
\hline & 0.0319 & -0.0987 & 0.4139 & 0.4811 & 23.5971 & -0.1795 & -0.3827 & -0.1421 & 0.3254 \\
\hline & $(5.06)$ & $(-7.57)$ & ( 6.48$)$ & ( 18.76$)$ & ( 3.64$)$ & $(-3.92)$ & $(-8.76)$ & $(-0.87)$ & ( 2.14$)$ \\
\hline \multirow{8}{*}{$\begin{array}{l}1991.01 \\
-1995.12\end{array}$} & 0.0457 & -0.2716 & & & & & & & \\
\hline & ( 30.19$)$ & $(-18.42)$ & & & & & & & \\
\hline & 0.0346 & & 1.5370 & & & & & & \\
\hline & $(28.96)$ & & ( 15.43$)$ & & & & & & \\
\hline & 0.0383 & -0.2495 & 1.2911 & & & & & & \\
\hline & $(28.96)$ & $(-18.82)$ & ( 16.99) & & & & & & \\
\hline & 0.0341 & -0.1031 & 0.3658 & 0.5662 & 29.6493 & -0.0762 & -0.4690 & -0.2590 & 0.3146 \\
\hline & $(7.26)$ & $(-11.23)$ & ( 7.12) & ( 15.02$)$ & $(10.72)$ & $(-1.64)$ & $(-7.72)$ & $(-1.57)$ & ( 3.05$)$ \\
\hline \multirow{8}{*}{$\begin{array}{l}1996.01 \\
-2000.12\end{array}$} & 0.0492 & -0.2438 & & & & & & & \\
\hline & $(11.81)$ & $(-11.58)$ & & & & & & & \\
\hline & 0.0387 & & 1.6297 & & & & & & \\
\hline & $(10.99)$ & & $(10.47)$ & & & & & & \\
\hline & 0.0416 & -0.2154 & 1.2503 & & & & & & \\
\hline & $(11.72)$ & $(-11.71)$ & $(10.50)$ & & & & & & \\
\hline & 0.0616 & -0.1260 & 0.5309 & 0.3368 & 32.4752 & -0.0966 & -0.7391 & -0.4161 & 0.2837 \\
\hline & $(8.14)$ & $(-7.95)$ & $(7.24)$ & ( 8.48) & $(4.74)$ & $(-0.93)$ & $(-8.92)$ & $(-0.70)$ & ( 1.46$)$ \\
\hline
\end{tabular}

Note.-The table presents results of cross-sectional regressions of variance of returns (VR) on return-onequity (ROE), variance of return-on-equity (VROE) and other variables at the firm level,

$$
\begin{aligned}
\mathrm{VR}_{i t}^{\text {raw }}= & \phi_{1}+\phi_{2} \mathrm{ROE}_{i, t-1}+\phi_{3} \mathrm{VROE}_{i, t-1}+\phi_{4} \mathrm{VR}_{i, t-1}^{\text {raw }}+\phi_{5} R_{t} \\
& +\phi_{6} \mathrm{AGE}_{i t}+\phi_{7} \mathrm{SZ}_{i, t-1}+\phi_{8} \mathrm{LV}_{i, t-1}+\phi_{9} \mathrm{BM}_{i, t-1}+\varepsilon_{i t},
\end{aligned}
$$

where VR is the variance of raw returns, $R_{t}$ the contemporaneous return, AGE the log of number of years in the CRSP, SZ the log of equity size, LV the leverage defined as long-term debt divided by total assets, and BM the log of book-to-market equity ratio. Estimates of $\phi_{5}$ to $\phi_{9}$ are multiplied by 100. The numbers in parentheses are t-ratios with conditional heteroskedasticity and three-month lag autocorrelation adjustments. 
Table 4 Cross-sectional Regression of IVR on IROE, IVROE and Other Variables

\begin{tabular}{|c|c|c|c|c|c|c|c|c|c|}
\hline Period & $\phi_{1}$ & $\phi_{2}$ & $\phi_{3}$ & $\phi_{4}$ & $\phi_{5}$ & $\phi_{6}$ & $\phi_{7}$ & $\phi_{8}$ & $\phi_{9}$ \\
\hline \multirow[t]{7}{*}{$\begin{array}{l}1975.01 \\
-2000.12\end{array}$} & $\begin{array}{l}0.0058 \\
(5.20)\end{array}$ & $\begin{array}{l}-0.1011 \\
(-11.61)\end{array}$ & & & & & & & \\
\hline & 0.0066 & & 0.4460 & & & & & & \\
\hline & $(5.58)$ & & $(4.71)$ & & & & & & \\
\hline & 0.0056 & -0.1004 & 0.4709 & & & & & & \\
\hline & ( 5.09$)$ & $(-11.30)$ & $(5.25)$ & & & & & & \\
\hline & 0.0002 & -0.0671 & 0.2286 & 0.3894 & 18.4870 & 0.1239 & -0.1100 & 0.3213 & 0.2980 \\
\hline & $(0.09)$ & $(-12.07)$ & $(2.94)$ & (19.35) & $(7.76)$ & ( 3.77$)$ & $(-3.64)$ & $(2.33)$ & $(5.50)$ \\
\hline \multirow{8}{*}{$\begin{array}{l}1976.01 \\
-1980.12\end{array}$} & 0.0013 & -0.0095 & & & & & & & \\
\hline & $(2.62)$ & $(-1.49)$ & & & & & & & \\
\hline & 0.0013 & & -0.3248 & & & & & & \\
\hline & $(2.55)$ & & $(-0.85)$ & & & & & & \\
\hline & 0.0014 & -0.0069 & -0.2073 & & & & & & \\
\hline & $(2.65)$ & $(-1.05)$ & $(-0.56)$ & & & & & & \\
\hline & -0.0031 & -0.0117 & -0.2143 & 0.1668 & 5.4070 & 0.0361 & 0.0265 & 0.0029 & 0.0624 \\
\hline & $(-3.29)$ & $(-1.77)$ & $(-0.59)$ & $(5.58)$ & $(7.27)$ & $(3.20)$ & $(2.23)$ & $(0.05)$ & ( 1.88$)$ \\
\hline \multirow{8}{*}{$\begin{array}{l}1981.01 \\
-1985.12\end{array}$} & -0.0006 & -0.0636 & & & & & & & \\
\hline & $(-1.10)$ & $(-7.74)$ & & & & & & & \\
\hline & -0.0001 & & 0.6441 & & & & & & \\
\hline & $(-0.12)$ & & (11.30) & & & & & & \\
\hline & -0.0007 & -0.0576 & 0.5845 & & & & & & \\
\hline & $(-1.11)$ & $(-7.63)$ & ( 13.56$)$ & & & & & & \\
\hline & -0.0036 & -0.0435 & 0.3740 & 0.3888 & 6.3391 & -0.0851 & 0.0819 & 0.0807 & 0.1915 \\
\hline & $(-3.82)$ & $(-6.97)$ & ( 10.11) & (14.54) & $(5.27)$ & $(-3.93)$ & ( 6.82$)$ & $(0.91)$ & (5.64) \\
\hline \multirow{8}{*}{$\begin{array}{l}1986.01 \\
-1990.12\end{array}$} & 0.0076 & -0.1184 & & & & & & & \\
\hline & $(2.80)$ & $(-6.72)$ & & & & & & & \\
\hline & 0.0084 & & 0.7504 & & & & & & \\
\hline & ( 2.93) & & ( 6.30$)$ & & & & & & \\
\hline & 0.0070 & -0.1203 & 0.7734 & & & & & & \\
\hline & $(2.61)$ & $(-6.77)$ & $(6.44)$ & & & & & & \\
\hline & 0.0048 & -0.0849 & 0.3992 & 0.4277 & 23.4088 & 0.0930 & -0.2122 & 0.4613 & 0.3602 \\
\hline & $(0.73)$ & $(-7.11)$ & $(5.62)$ & $(16.21)$ & ( 3.48$)$ & ( 1.72$)$ & $(-3.71)$ & $(2.40)$ & ( 2.78$)$ \\
\hline \multirow{8}{*}{$\begin{array}{l}1991.01 \\
-1995.12\end{array}$} & 0.0101 & -0.1778 & & & & & & & \\
\hline & $(5.66)$ & $(-12.74)$ & & & & & & & \\
\hline & 0.0120 & & 0.6742 & & & & & & \\
\hline & ( 5.87$)$ & & ( 7.13$)$ & & & & & & \\
\hline & 0.0097 & -0.1795 & 0.6945 & & & & & & \\
\hline & $(5.64)$ & $(-13.23)$ & $(7.69)$ & & & & & & \\
\hline & 0.0010 & -0.0953 & 0.2198 & 0.5525 & 26.5808 & 0.2506 & -0.2325 & 0.3954 & 0.3203 \\
\hline & $(0.31)$ & $(-11.12)$ & $(7.21)$ & $(19.88)$ & $(9.19)$ & ( 5.39$)$ & $(-4.37)$ & ( 2.15$)$ & ( 3.67$)$ \\
\hline \multirow{8}{*}{$\begin{array}{l}1996.01 \\
-2000.12\end{array}$} & 0.0105 & -0.1365 & & & & & & & \\
\hline & $(3.00)$ & $(-14.78)$ & & & & & & & \\
\hline & 0.0115 & & 0.4860 & & & & & & \\
\hline & ( 3.20$)$ & & ( 8.91) & & & & & & \\
\hline & 0.0106 & -0.1379 & 0.5096 & & & & & & \\
\hline & ( 3.01$)$ & $(-14.98)$ & $(9.52)$ & & & & & & \\
\hline & 0.0019 & -0.0995 & 0.3549 & 0.4107 & 30.7022 & 0.3250 & -0.2131 & 0.6705 & 0.5584 \\
\hline & $(0.23)$ & $(-10.22)$ & ( 6.31$)$ & $(9.46)$ & $(4.39)$ & ( 2.84$)$ & $(-2.06)$ & ( 1.10$)$ & $(2.86)$ \\
\hline
\end{tabular}

Note.-The table presents results of cross-sectional regressions of incremental variance of returns (IVR) on incremental return-on-equity (IROE), incremental variance of return-on-equity (IVROE) and other variables at the firm level,

$$
\begin{aligned}
\mathrm{IVR}_{i t}^{\text {raw }}= & \phi_{1}+\phi_{2} \mathrm{IROE}_{i, t-1}+\phi_{3} \mathrm{IVROE}_{i, t-1}+\phi_{4} \mathrm{IVR}_{i, t-1}^{\text {raw }}+\phi_{5} R_{t} \\
& +\phi_{6} \mathrm{AGE}_{i t}+\phi_{7} \mathrm{SZ}_{i, t-1}+\phi_{8} \mathrm{LV}_{i, t-1}+\phi_{9} \mathrm{BM}_{i, t-1}+\varepsilon_{i t},
\end{aligned}
$$

where IVR is the incremental variance of raw returns, $R_{t}$ the contemporaneous return, AGE the log of number of years in the CRSP, SZ the log of equity size, LV the leverage defined as long-term debt divided by total assets, and BM the log of book-to-market equity ratio. Estimates of $\phi_{5}$ to $\phi_{9}$ are multiplied by 100 . The numbers in parentheses are t-ratios with conditional heteroskedasticity and three-month lag autocorrelation adjustments. 
Table 5 Time-series Regression of VR on ROE, VROE and CVROE

A. Equally weighted average variance of raw returns, $\mathrm{VR}_{\text {ew, }}^{r a w}$

$\begin{array}{cccccc}\theta_{0} & 100000 \cdot \theta_{1} & \theta_{2} & \theta_{3} & \theta_{4} & R^{2} \\ 0.0066 & 16.3413 & & & 0.5199 \\ (3.3948) & (10.6384) & & & & \\ 0.0329 & 6.6187 & -0.7708 & & & 0.5663 \\ (3.5951) & (2.0698) & (-2.8527) & & & 0.5507 \\ 0.0023 & 4.6463 & & (2.0686 & & \\ (1.2072) & (0.9509) & & & & 0.5270) \\ 0.0026 & 2.3566 & & & & \\ (1.0541) & (0.4380) & & & & \\ 0.0254 & 0.4455 & -0.6342 & 3.4222 & & 0.5783789 \\ (2.7996) & (0.0907) & (-2.3717) & (1.9714) & & \\ 0.0203 & -0.9437 & -0.5092 & 3.1002 & 0.7661 & 0.5801 \\ (1.9255) & (-0.1727) & (-1.8041) & (1.5556) & (0.5047) & \end{array}$

B. Equally weighted average variance of market-adjusted returns, $\mathrm{VR}_{e w, t}^{a d j}$

\begin{tabular}{cccccc}
$\theta_{0}$ & $100000 \cdot \theta_{1}$ & $\theta_{2}$ & $\theta_{3}$ & $\theta_{4}$ & $R^{2}$ \\
0.0057 & 16.4529 & & & 0.5478 \\
$(2.9726)$ & $(10.7564)$ & & & \\
0.0323 & 6.6013 & -0.7807 & & & 0.5983 \\
$(3.5440)$ & $(2.0807)$ & $(-2.8833)$ & & & 0.5815 \\
0.0013 & 4.6618 & & $(2.8757)$ & & \\
$(0.6764)$ & $(0.9987)$ & & & 2.8900 & 0.5916 \\
0.0016 & 2.4568 & & & & \\
$(0.6596)$ & $(0.4635)$ & & & & $0.5019)$ \\
0.0245 & 0.6558 & -0.6373 & 3.3604 & & \\
$(2.7087)$ & $(0.1395)$ & $(-2.3711)$ & $(2.0532)$ & & \\
0.0197 & -0.6169 & -0.5178 & 3.0491 & 0.7225 & 0.6123 \\
$(1.9458)$ & $(-0.1167)$ & $(-1.8966)$ & $(1.6134)$ & $(0.4948)$ & \\
\hline
\end{tabular}


Table 5 (cont'd)

C: Value-weighted average variance of raw returns, $\mathrm{VR}_{v w, t}^{r a w}$

$\begin{array}{cccccc}\theta_{0} & 100000 \cdot \theta_{1} & \theta_{2} & \theta_{3} & \theta_{4} & R^{2} \\ 0.0035 & 3.4547 & & & & 0.1477 \\ (3.6394) & (4.0520) & & & & 0.1653 \\ -0.0037 & 2.6475 & 0.1910 & & & 0.2896 \\ (-1.1954) & (3.3539) & (2.6705) & & & 0.1609 \\ 0.0050 & -5.9201 & & (3.6577) & & \\ (7.0267) & (-2.7692) & & & 0.6553 & 0.2905 \\ 0.0026 & 0.2712 & & & & \\ (1.6769) & (0.1234) & & & & \\ 0.0033 & -5.8957 & 0.0440 & 9.2892 & & \\ (1.1316) & (-2.7061) & (0.6161) & (3.3817) & & \\ 0.0026 & -6.4209 & 0.0576 & 9.0433 & 0.1462 & \\ (0.7362) & (-2.2810) & (0.7471) & (3.4897) & (0.4186) & \end{array}$

D: Value-weighted average variance of market adjusted returns, $\mathrm{VR}_{v w, t}^{a d j}$

$\begin{array}{cccccc}\theta_{0} & 100000 \cdot \theta_{1} & \theta_{2} & \theta_{3} & \theta_{4} & R^{2} \\ 0.0025 & 3.0736 & & & & 0.2497 \\ (3.2262) & (4.2728) & & & & 0.2758 \\ -0.0036 & 2.3993 & 0.1595 & & & 0.4755 \\ (-1.4333) & (3.6930) & (2.7949) & & & \\ 0.0038 & -5.0222 & & 8.2063 & & 0.2678 \\ (7.7371) & (-2.9613) & & (3.8911) & & \\ 0.0018 & 0.5698 & & & 0.5152 & 0.4765 \\ (1.4263) & (0.3462) & & & & \\ 0.0025 & -5.0044 & 0.0324 & 8.0496 & & 0.477080) \\ (1.1811) & (-2.9047) & (0.6085) & (3.6544) & & \\ 0.0020 & -5.3277 & 0.0410 & 7.8996 & 0.0895 & \\ (0.8272) & (-2.4618) & (0.7247) & (3.7704) & (0.3551) & \end{array}$

Note.-The table presents results of time-series regressions of value-weighted and equally weighted average variance (VR) of raw returns or market-adjusted returns on the corresponding return on equity $(\mathrm{ROE})$, variance of return on equity (VROE), and cross-sectional variance of return-on-equity (CVROE),

$$
\mathrm{VR}_{t}=\theta_{0}+\theta_{1} t+\theta_{2} \mathrm{ROE}_{t-1}+\theta_{3} \mathrm{VROE}_{t-1}+\theta_{4} \mathrm{CVROE}_{t-1}+\varepsilon_{t},
$$

where $\mathrm{VR}_{t}, \mathrm{ROE}_{t-1}$, and $\mathrm{VROE}_{t-1}$ are either all value-weighted averages or all equally weighted averages. The numbers in parentheses are t-ratios. The numbers in square brackets are the NeweyWest t-ratios with three-month lag adjustments. The sample period is 1976-2000. 
Table 6 Time-series Regression of IVR on IROE, IVROE and ICVROE

A. Equally weighted average of incremental variance of raw returns, $\operatorname{IVR}_{e w, t}^{\text {raw }}$

$\begin{array}{cccccc}\theta_{0} & 100000 \cdot \theta_{1} & \theta_{2} & \theta_{3} & \theta_{4} & R^{2} \\ -0.0043 & 6.7800 & & & & 0.1810 \\ (-2.9770) & (5.1529) & & & & 0.2337 \\ -0.0051 & 4.7564 & -0.5375 & & & \\ (-3.2154) & (3.0758) & (-2.9878) & & & 0.1996 \\ -0.0059 & 7.2735 & & (1.5251) & & \\ (-5.1626) & (6.0394) & & & 4.9440 & 0.3075 \\ -0.0112 & -15.0905 & & & & \\ (-4.6344) & (-2.8181) & & & & 0.8829) \\ -0.0048 & 4.4311 & -0.5912 & -0.9092 & & \\ (-3.5112) & (2.9821) & (-2.1896) & (-0.2711) & & \\ -0.0103 & -14.5130 & -0.2422 & -1.7079 & 4.5806 & 0.3125 \\ (-4.7876) & (-2.1580) & (-1.2952) & (-0.5224) & (2.9583) & \end{array}$

B. Equally weighted average of incremental variance of market-adjusted returns, IVR ew,$t^{a d j}$

\begin{tabular}{cccccc}
$\theta_{0}$ & $100000 \cdot \theta_{1}$ & $\theta_{2}$ & $\theta_{3}$ & $\theta_{4}$ & $R^{2}$ \\
-0.0080 & 6.5700 & & & & 0.1943 \\
$(-5.8360)$ & $(5.1203)$ & & & & 0.2528 \\
-0.0088 & 4.5754 & -0.5285 & & & 0.2113 \\
$(-5.7764)$ & $(3.0638)$ & $(-3.0579)$ & & & \\
-0.0094 & 7.0096 & & $(1.4613)$ & & 0.3345 \\
$(-8.6257)$ & $(5.9811)$ & & & $(3.6813)$ & \\
-0.0147 & -14.5366 & & & & 0.2548 \\
$(-6.0342)$ & $(-2.6814)$ & & -1.5216 & & \\
-0.0083 & 4.0300 & -0.6184 & $-0.4980)$ & & 0.3424 \\
$(-6.2398)$ & $(2.8928)$ & $(-2.4107)$ & -2.4258 & 4.4780 & \\
-0.0136 & -14.4808 & -0.2691 & $(-0.8144)$ & $(2.8090)$ & \\
$(-6.2311)$ & $(-2.1089)$ & $(-1.5994)$ & $(-0.59)$ & & \\
\hline
\end{tabular}


Table 6 (cont'd)

C. Value-weighted average of incremental variance of raw returns, $\mathrm{IVR}_{v w, t}^{r a w}$

$\begin{array}{cccccc}\theta_{0} & 100000 \cdot \theta_{1} & \theta_{2} & \theta_{3} & \theta_{4} & R^{2} \\ -0.0005 & 1.2946 & & & & 0.0275 \\ (-0.5795) & (1.8670) & & & & 0.0303 \\ -0.0003 & 1.0772 & 0.0655 & & & \\ (-0.3946) & (1.4345) & (0.7345) & & & \\ -0.0001 & 1.4761 & & -3.7415 & & 0.0451 \\ (-0.0956) & (1.9949) & & (-1.4208) & & \\ -0.0013 & -1.3316 & & & 0.5970 & 0.0351 \\ (-0.9872) & (-0.5947) & & & (1.0824) & \\ -0.0001 & 1.5010 & -0.0066 & -3.8056 & & 0.0451 \\ (-0.0974) & (1.5476) & (-0.0604) & (-1.2152) & & \\ -0.0014 & -3.5537 & 0.0335 & -5.1921 & 1.1342 & 0.0677 \\ (-1.0923) & (-1.5163) & (0.4101) & (-1.4245) & (1.7095) & \end{array}$

D. Value-weighted average of incremental variance of market-adjusted returns, $\mathrm{IVR}_{v w, t}^{a d j}$

\begin{tabular}{cccccc}
$\theta_{0}$ & $100000 \cdot \theta_{1}$ & $\theta_{2}$ & $\theta_{3}$ & $\theta_{4}$ & $R^{2}$ \\
-0.0008 & 1.1091 & & & & 0.0554 \\
$(-1.2555)$ & $(1.9418)$ & & & & 0.0609 \\
-0.0006 & 0.9244 & 0.0556 & & & \\
$(-1.0469)$ & $(1.5446)$ & $(0.8119)$ & & & \\
-0.0003 & 1.3047 & & -4.0337 & & 0.1113 \\
$(-0.7456)$ & $(2.1865)$ & & $(-2.2510)$ & & 0.1123 \\
-0.0003 & 1.4016 & -0.0255 & -4.2834 & & \\
$(-0.7251)$ & $(1.8654)$ & $(-0.3245)$ & $(-2.0536)$ & & 0.4721 \\
-0.0014 & -0.9684 & & & 0.0690 \\
$(-1.5123)$ & $(-0.6025)$ & & & $(1.2002)$ & \\
-0.0015 & -2.0153 & 0.0944 & & 0.6387 & 0.0831 \\
$(-1.5139)$ & $(-1.4205)$ & $(1.6722)$ & & $(1.6814)$ & \\
-0.0015 & -3.0344 & & -5.6987 & 1.0043 & 0.1633 \\
$(-1.7800)$ & $(-1.6893)$ & & $(-2.5859)$ & $(2.1065)$ & \\
-0.0015 & -3.1239 & 0.0110 & -5.6097 & 1.0154 & 0.1635 \\
$(-1.7778)$ & $(-2.0124)$ & $(0.1889)$ & $(-2.3519)$ & $(2.2682)$ & \\
\hline
\end{tabular}

Note.-The table presents results of time-series regressions of value-weighted and equally weighted averages of incremental variance (IVR) of the raw returns or the market-adjusted returns on the corresponding incremental return-on-equity (IROE), incremental variance of return-on-equity (IVROE), and incremental cross-sectional variance of return-on-equity (ICVROE),

$$
\mathrm{IVR}_{t}=\theta_{0}+\theta_{1} t+\theta_{2} \mathrm{IROE}_{t-1}+\theta_{3} \mathrm{IVROE}_{t-1}+\theta_{4} \mathrm{ICVROE}_{t-1}+\varepsilon_{t},
$$

where $\mathrm{IVR}_{t}, \mathrm{IROE}_{t-1}$ and $\mathrm{IVROE}_{t-1}$ are either all value-weighted averages or all equally weighted averages. The numbers in parenthesis are t-ratios. The numbers in square brackets are the Newey-West t-ratio with three-month lag adjustments. The sample period is 1976-2000. 
Equally weighted average variance of returns

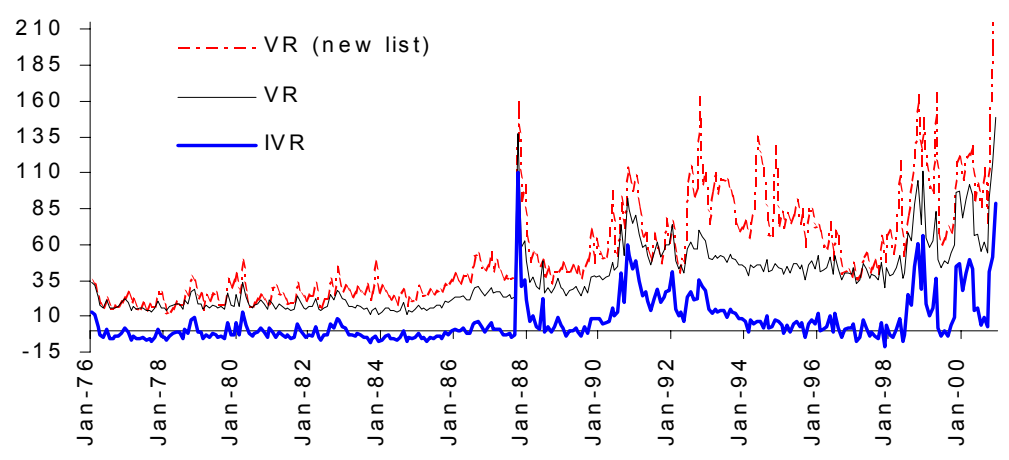

Value-weighted average variance of returns

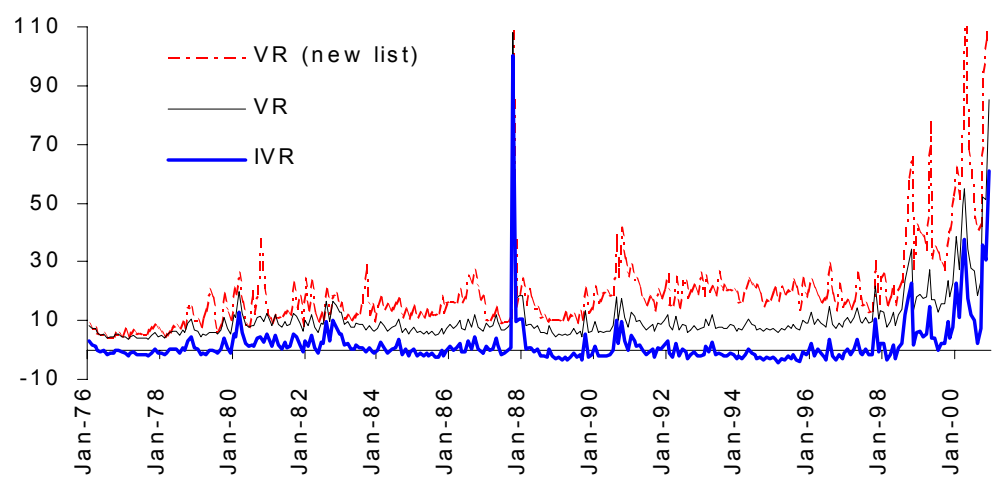

Figure 1: Average variance of raw returns. VR is the time series of average variance of raw returns. IVR is the time series of average incremental variance of raw returns. The monthly variances are multiplied by 1200 . 
Equally weighted average ROE

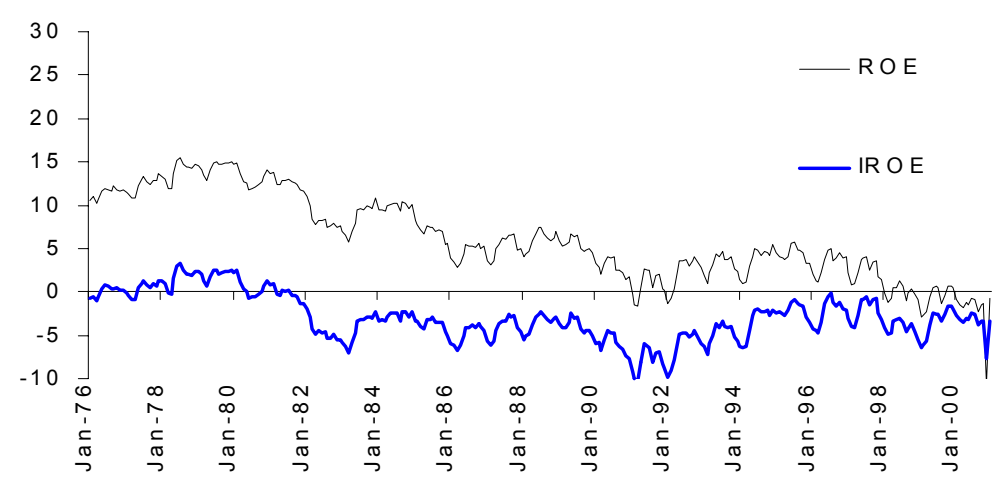

Value-weighted average ROE

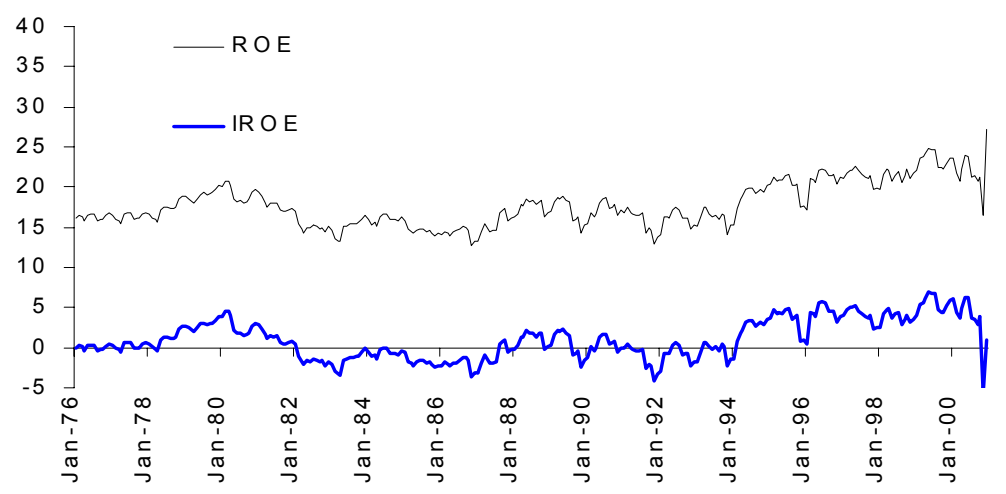

Figure 2: Average ROE. This figure plots the time series of equally weighted and value-weighted average ROE and incremental ROE. The quarterly ROEs are multiplied by 400 . 
Equally weighted average VROE

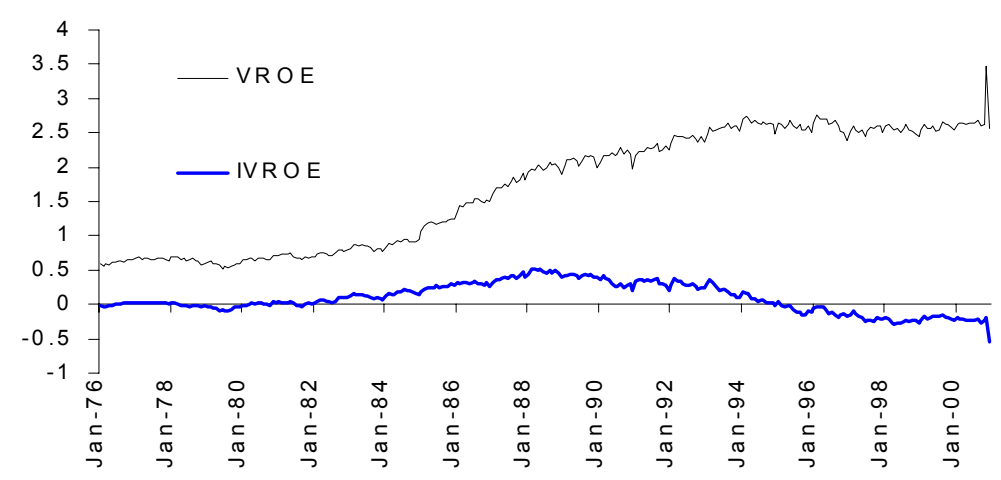

Value-weighted average VROE

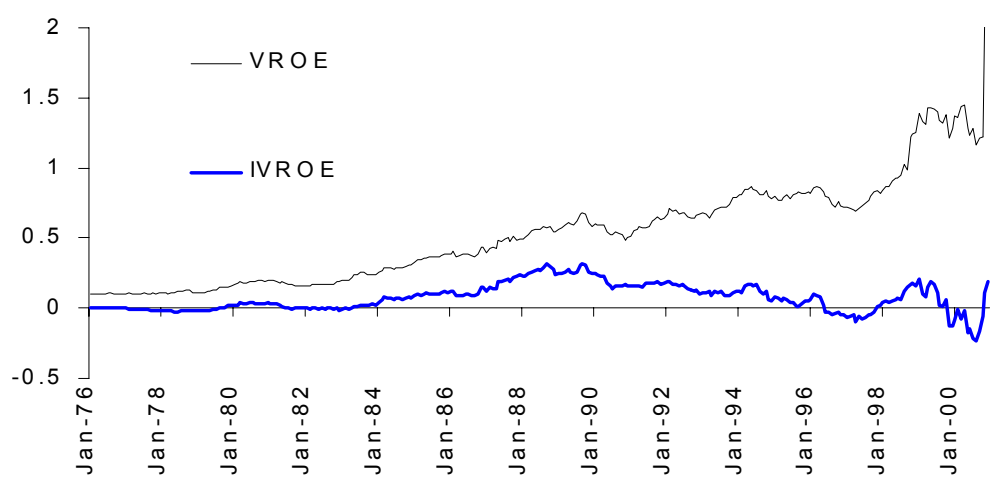

Figure 3: Average VROE. This figure plots the time series of equally weighted and value-weighted VROE and incremental VROE. The quarterly VROEs are multiplied by 400 . 
Average VR of ROE-sorted quintiles

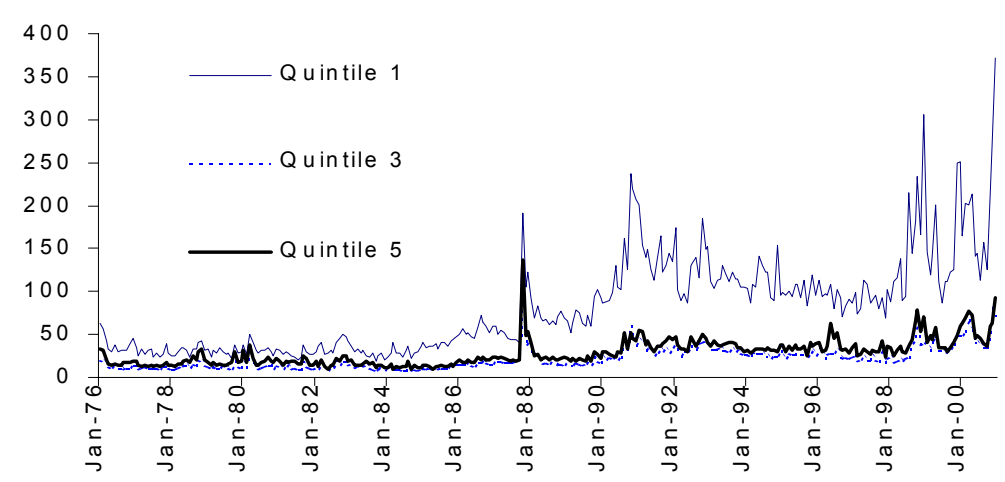

Average VR of VROE-sorted quintiles

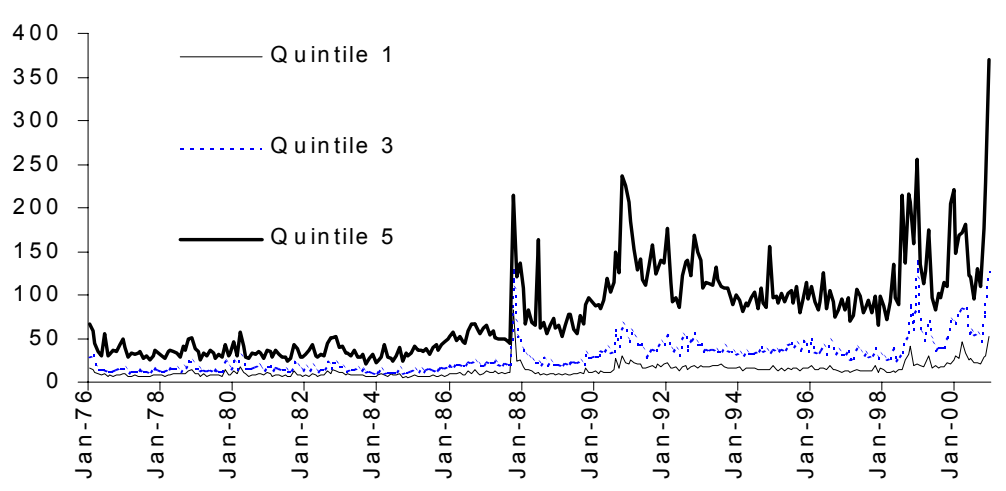

Figure 4: Simple average variance of ROE-sorted and VROE-sorted quintiles. This figure plots the time series of the simple average variance of ROE-sorted and VROEsorted quintiles 1 (lowest ROE and VROE), 3 and 5 (highest ROE and VROE). The monthly variances of returns are multiplied by 1200 . 